\title{
Glucose-Binding of Periplasmic Protein GltB Activates GtrS-GltR Two-Component System in Pseudomonas aeruginosa
}

\author{
Chenchen $X u^{1,2} \mathbb{D}$, Qiao Cao ${ }^{2}$ and Lefu Lan $1,2,3,4, * \mathbb{D}$ \\ 1 University of Chinese Academy of Sciences, No.19A Yuquan Road, Beijing 100049, China; \\ 201528012342123@simm.ac.cn \\ 2 State Key Laboratory of Drug Research, Shanghai Institute of Materia Medica, Chinese Academy of Sciences, \\ Shanghai 201203, China; caoqiao@simm.ac.cn \\ 3 School of Pharmaceutical Science and Technology, Hangzhou Institute for Advanced Study, UCAS, \\ Hangzhou 310024, China \\ 4 NMPA Key Laboratory for Testing Technology of Pharmaceutical Microbiology, Shanghai Institute for Food \\ and Drug Control, Shanghai 201203, China \\ * Correspondence: llan@simm.ac.cn; Tel.: +86-21-5080-3109; Fax: +86-21-5080-7088
}

Citation: Xu, C.; Cao, Q.; Lan, L. Glucose-Binding of Periplasmic Protein GltB Activates GtrS-GltR Two-Component System in Pseudomonas aeruginosa. Microorganisms 2021, 9, 447. https://doi.org/10.3390/ microorganisms 9020447

Academic Editor: Monica C. Gestal

Received: 27 January 2021

Accepted: 18 February 2021

Published: 21 February 2021

Publisher's Note: MDPI stays neutral with regard to jurisdictional claims in published maps and institutional affiliations.

Copyright: (c) 2021 by the authors. Licensee MDPI, Basel, Switzerland. This article is an open access article distributed under the terms and conditions of the Creative Commons Attribution (CC BY) license (https:// creativecommons.org/licenses/by/ $4.0 /)$.

\begin{abstract}
A two-component system GtrS-GltR is required for glucose transport activity in P. aeruginosa and plays a key role during $P$. aeruginosa-host interactions. However, the mechanism of action of GtrS-GltR has not been definitively established. Here, we show that $g l t B$, which encodes a periplasmic glucose binding protein, is essential for the glucose-induced activation of GtrS-GltR in P. aeruginosa. We determined that GltB is capable of binding to membrane regulatory proteins including GtrS, the sensor kinase of the GtrS-GltR TCS. We observed that alanine substitution of glucose-binding residues abolishes the ability of GltB to promote the activation of GtrS-GltR. Importantly, like the gtrS deletion mutant, gltB deletion mutant showed attenuated virulence in both Drosophila melanogaster and mouse models of infection. In addition, using CHIP-seq experiments, we showed that the promoter of gltB is the major in vivo target of GltR. Collectively, these data suggest that periplasmic binding protein GltB and GtrS-GltR TCS form a complex regulatory circuit that regulates the virulence of P. aeruginosa in response to glucose.
\end{abstract}

Keywords: Pseudomonas aeruginosa; Glucose; periplasmic binding protein; two-component system; transcriptional regulation

\section{Introduction}

Glucose is an essential nutrient for the human body, serving as a primary fuel for energy production [1]. Many studies have also suggested that pathogens can exploit glucose as either a nutrient or a signal molecule that induces virulence functions [2-10]. Indeed, glucose acquisition is essential for the full virulence potential of pathogenic bacteria [11,12] including Pseudomonas aeruginosa, a major cause of nosocomial infection as well as infection in hosts with compromised defenses $[13,14]$. Recently, the World Health Organization has categorized P. aeruginosa as a critical priority pathogen that is in urgent need of new antibiotics [15,16]. Establishing a deeper understanding of how P. aeruginosa senses and responds to glucose may allow for the rational design of improved therapies to treat or prevent infections caused by this formidable pathogen [17-19].

It has been proposed that, in P. aeruginosa, when glucose passes the outer membrane through the OprB porin and reaches the periplasm, it can be transported by an ABC transport system (i.e., $A B C^{\text {GltBFGK}}$, also designated as $A B C^{G t s A B C D}$ ) to the cytoplasm, or it can be oxidized in the periplasm by glucose dehydrogenase (Gcd) and gluconate dehydrogenase (Gad) to gluconate and 2-ketogluconate (2-KG) [20-24] (Figure 1A). Gluconate and 2-KG are subsequently transported to the cytoplasm via transporters GntP and KguT, respectively [22,25] (Figure 1A). Both the phosphorylative pathway, which converts glucose to 
6-phosphogluoconate by the combined action of glucokinase (GIK), glucose 6-phosphate dehydrogenase (Zwf), and 6-phosphogluconolactonase (Pgl) (Figure 1A), and the direct oxidative pathway, wherein glucose is oxidized to gluconate, 2-ketogluconate and then subsequently to 6-phosphogluconate (Figure 1A), are active under aerobic conditions, while the phosphorylative pathway can substitute for the oxidative pathway under anaerobic conditions [21].

Genes encoding the $P$. aeruginosa glucose catabolism are organized in operons and are under the control of different regulators (i.e., HexR, PtxS, PtxR, GntR, and GtrSGltR) [23]. Among them, response regulator (RR) GltR, which forms a two-component system with its cognate sensor kinase (SK) GtrS [26], is required for glucose transport activity in P. aeruginosa PAO1 [20,27], presumably by activating the transcription of gltBFGK ( $g$ ts $A B C D$ )-oprB operon that encodes OprB porin and the glucose transport system ABCGltBFGK [28]. However, these results were somehow contrast to the findings of Daddaoua et al. [26], where GltR is a transcriptional repressor that is released from its target operators of glucose metabolism genes upon phosphorylation.

Although discrepancy exists, results from previous studies show a conserved role of GtrS-GltR on glucose utilization in different Pseudomonas species including P. aeruginosa $[20,26,29]$. Interestingly, 2-KG and 6-phosphogluconate (6PG), two metabolic intermediates of glucose utilization pathways, can bind to ligand-binding domain of GtrS, leading to increase GtrS autophosphorylation and GltR phosphorylation activity [26]. These observations suggest a physiological relevance of GtrS-GltR in glucose metabolism. Importantly, GtrS plays a key role during P. aeruginosa-host interactions and is required for optimal colonization and dissemination in a mouse model of infection [28]. Intrigued by these findings, in this study, we decided to investigate the mechanism of action of GtrS-GltR TCS in P. aeruginosa PAO1.

\section{Experimental Procedures}

\subsection{Bacterial Strains, Plasmids, and Culture Conditions}

The bacterial strains and plasmids used in this study are listed in Table S1. Unless noted otherwise, E. coli cultures were grown in Luria-Bertani (LB) medium. P. aeruginosa PAO1 [19] and its derivatives were grown in LB medium, Pyocyanin production broth (PB medium) (20 g peptone, $1.4 \mathrm{~g} \mathrm{MgCl}_{2}, 10 \mathrm{~g} \mathrm{~K}_{2} \mathrm{~S}_{4}, 20 \mathrm{~mL}$ glycerol per liter; $\mathrm{pH}$ 7.0) [30], minimal medium (MM) $\left(6.8 \mathrm{~g} \mathrm{Na}_{2} \mathrm{HPO}_{4}, 3 \mathrm{~g} \mathrm{KH}_{2} \mathrm{PO}_{4}, 0.5 \mathrm{~g} \mathrm{NaCl}, 0.24 \mathrm{~g} \mathrm{MgSO}_{4}, 1 \mathrm{~g} \mathrm{NH}_{4} \mathrm{Cl}\right.$; $\mathrm{pH}$ 7.4) supplemented with $10 \mathrm{mM}$ glucose, gluconate or 2-KG as the sole carbon source, M8 minimal medium (MM) $\left(6.8 \mathrm{~g} \mathrm{Na}_{2} \mathrm{HPO}_{4}, 3 \mathrm{~g} \mathrm{KH}_{2} \mathrm{PO}_{4}, 0.5 \mathrm{~g} \mathrm{NaCl}, 0.24 \mathrm{~g} \mathrm{MgSO}_{4}, 0.82 \mathrm{~g}\right.$ sodium acetate, 0.5 g glutamate per liter; $\mathrm{pH} 7.4)$, or $\mathrm{M} 9$ minimal medium (MM) (6.8 g $\mathrm{Na}_{2} \mathrm{HPO}_{4}, 3 \mathrm{~g} \mathrm{KH}_{2} \mathrm{PO}_{4}, 0.5 \mathrm{~g} \mathrm{NaCl}, 0.24 \mathrm{~g} \mathrm{MgSO}_{4}, 1 \mathrm{~g} \mathrm{NH} 4 \mathrm{Cl}, 0.96 \mathrm{~g}$ citrate, $2.5 \mathrm{~mL}$ of A9 solution; $\mathrm{pH} 7.4$ ) $[25,31]$. A9 solution was composed of the following (in milligrams per liter): $\mathrm{HBO}_{3}, 300 ; \mathrm{ZnCl}_{2}, 50 ; \mathrm{MnCl}_{2} \cdot 4 \mathrm{H}_{2} \mathrm{O}, 30 ; \mathrm{CoCl}_{2}, 200 ; \mathrm{CuCl}_{2} \cdot 2 \mathrm{H}_{2} \mathrm{O}, 10 ; \mathrm{NiCl}_{2} \cdot 6 \mathrm{H}_{2} \mathrm{O}, 20$; and $\mathrm{NaMoO}_{4} \cdot 2 \mathrm{H}_{2} \mathrm{O}, 30$. Bacterial cultures were incubated at $37^{\circ} \mathrm{C}$ with shaking $(250 \mathrm{rpm})$ under aerobic condition. For plasmid maintenance, antibiotics were used at the following concentrations where appropriate: for E. coli, carbenicillin at $100 \mu \mathrm{g} / \mathrm{mL}$, kanamycin at $50 \mu \mathrm{g} / \mathrm{mL}$, tetracycline at $5 \mu \mathrm{g} / \mathrm{mL}$, and gentamicin at $10 \mu \mathrm{g} / \mathrm{mL}$; for P. aeruginosa, gentamicin at $50 \mu \mathrm{g} / \mathrm{mL}$ in LB or $150 \mu \mathrm{g} / \mathrm{mL}$ in Pseudomonas Isolation Agar (PIA; BD); tetracycline at $30 \mu \mathrm{g} / \mathrm{mL}$ in LB or $150 \mu \mathrm{g} / \mathrm{mL}$ in PIA; carbenicillin at $150 \mu \mathrm{g} / \mathrm{mL}$ in LB, PIA, and minimal medium.

\subsection{Construction of P. aeruginosa Mutants}

For gene replacement, a SacB-based strategy was employed as previously described [32]. To generate the $\Delta g l t B$ mutant strain, polymerase chain reactions (PCRs) were performed in order to amplify sequences upstream $(\sim 1.2 \mathrm{~kb})$ and downstream $(\sim 1.3 \mathrm{~kb})$ of the intended deletion. The upstream fragment was amplified from PAO1 genomic DNA using D-gltB-up-F (with EcoRI site) and D-gltB-up-R (with KpnI site), while the downstream fragment was amplified from PAO1 genomic DNA using D-gltB-down-F (with 
KpnI site) and D-gltB-down-R (with HindIII site). The two products were digested and then cloned into the EcoRI/HindIII-digested gene replacement vector $\mathrm{pEX} 18 \mathrm{Ap}$, yielding pEX18Ap::gltBUD. A $1.8 \mathrm{~kb}$ gentamicin resistance cassette was cut from pPS858 with KpnI and then cloned into pEX18Ap::gltBUD, yielding pEX18Ap::gltBUGD. The resultant plasmid was electroporated into PAO1 with selection for gentamicin resistance. Colonies were screened for gentamicin resistance and loss of sucrose $(5 \%)$ sensitivity, which indicates a double-cross-over event and the gene replacement. The deletion of gltB was confirmed by PCR.

A similar method was used to generate the $\Delta g t r S, \Delta g t r S-g l t R, \Delta g c d, \Delta g a d$ strains. Briefly, for the construction of $\Delta g t r S$, the upstream fragment $(\sim 1 \mathrm{~kb})$ of the intended deletion was amplified with primers D-gtrS-up-F (with EcoRI site) and D-gtrS-up-R (with BamHI site), and the downstream fragment $(\sim 1 \mathrm{~kb})$ was amplified with primer pair DgtrS-down-F (with BamHI site)/D-gtrS-down-R (with HindIII site). For the construction of $\Delta g t r S-g l t R$, the upstream fragment $(\sim 1.3 \mathrm{~kb})$ of the intended deletion was amplified with primer pair D-gltR-up-F/D-gltR-up-R (EcoRI/BamHI sites), while the downstream fragment $(\sim 1 \mathrm{~kb})$ was amplified with primer pair D-gtrS-down-F/D-gtrS-down-R (BamHI/HindIII). For the construction of $\Delta g c d$, the upstream fragment $(\sim 1.1 \mathrm{~kb})$ of the intended deletion was amplified with primers D-gcd-up-F (with EcoRI site) and D-gcdup-R (with BamHI site), and the downstream fragment $(\sim 1.1 \mathrm{~kb})$ was amplified with primers D-gcd-down-F (with BamHI site) and D-gcd-down-R (with HindIII site). For the construction of $\Delta g a d$, the upstream fragment $(\sim 1 \mathrm{~kb})$ of the intended deletion was amplified with primers D-gad-up-F (with EcoRI site) and D-gad-up-R (with BamHI site), and the downstream fragment $(\sim 1.1 \mathrm{~kb})$ was amplified with primers D-gad-down-F (with BamHI site) and D-gad-down-R (with HindIII site). A $1.8 \mathrm{~kb}$ gentamicin resistance cassette was cut from pPS858 and then cloned into the pEX18Ap::gtrSUD, pEX18Ap::gtrS-gltRUD, pEX18Ap::gcdUD and pEX18Ap::gadUD, yielding pEX18Ap::gtrSUGD, pEX18Ap::gtrSgltRUGD, pEX18Ap::gcdUGD, and pEX18Ap::gadUGD, respectively, as described above. To generate $\Delta g c d \Delta g t r S$-gltR mutant, the gentamicin resistance cassette of $\Delta g t r S$ - $g l t R$ was excised by using the plasmid pFLP2 that encoded Flp recombinase [32], and then the pEX18Ap::gcdUGD plasmid (Table S1) was electroporated into the $\Delta g t r S$-gltR (without gentamicin resistance cassette) in order to generate $\Delta g c d \Delta g t r S-g l t R$. All the primers used for PCRs are listed in Table S2. All the mutant strains were confirmed by PCR.

\subsection{Construction of Plasmids}

All the primers used for plasmid construction are listed in Table S2. For constructing pAK1900-gltB (p-gltB), a $\sim 1.3 \mathrm{~kb}$ PCR product covering $40 \mathrm{bp}$ of the $g l t B$ upstream region, the $g l t B$ gene, and $15 \mathrm{bp}$ downstream of $g l t B$ was amplified from PAO1 genomic DNA using primers gltB-comp-F (with HindIII site) and gltB-comp-R (with KpnI site). For generating pAK1900-gtrS (p-gtrS), a $1.5 \mathrm{~kb}$ PCR product covering $72 \mathrm{bp}$ of the gtrS upstream region, the $g t r S$ gene, and 9 bp downstream of $g t r S$ was amplified from PAO1 genomic DNA using primers gtrS-comp-F (with HindIII site) and gtrS-comp-R (with BamHI site). For generating pAK1900-gtrS-gltR (p-gtrS-gltR), a $\sim 2.3 \mathrm{~kb}$ PCR product covering $38 \mathrm{bp}$ of the $g l t R$ upstream region, the $g l t R$ and $g t r S$ genes, and $9 \mathrm{bp}$ downstream of $g t r S$ was amplified from PAO1 genomic DNA using primers gltR-comp-F (with HindIII site) and gtrS-comp-R (with BamHI site). To generate pAK1900-gcd (p-gcd), a $\sim 2.4 \mathrm{~kb}$ PCR product covering $30 \mathrm{bp}$ of the $g c d$ upstream region, the $g c d$ gene, and $8 \mathrm{bp}$ downstream of $g c d$ was amplified from PAO1 genomic DNA using primers $g c d$-comp-F (with HindIII site) and $g c d$-comp-R (with BamHI site). All the products were digested with the indicated enzymes and cloned into pAK1900 [33], and the direction of transcription of the cloned genes is in the same orientation as plac on pAK1900.

To construct pAK1900- $g l t B^{\mathrm{W} 33 \mathrm{~A}}$ (p-glt $B^{\mathrm{W} 33 \mathrm{~A}} ; g l t \mathrm{~B}^{\mathrm{W} 33 \mathrm{~A}}$, the tryptophan 33 of GltB was mutated to alanine), the primer pair GltB (W33A)-F/GltB (W33A)-R and a QuikChange II site-directed mutagenesis kit (Stratagene, Catalog\#:200518) were used. A similar method was used to generate the pAK1900-gltB ${ }^{\mathrm{W} 34 \mathrm{~A}}$ (p-gltB ${ }^{\mathrm{W} 34 \mathrm{~A}} ; g l t B^{\mathrm{W} 34 \mathrm{~A}}$, the tryptophan 34 of 
GltB was mutated to alanine), pAK1900- $g l t B^{\mathrm{K} 90 \mathrm{~A}}$ (p-gltB ${ }^{\mathrm{K} 90 \mathrm{~A}} ; g l t B^{\mathrm{K} 90 \mathrm{~A}}$, the lysine 90 of GltB was mutated to alanine), pAK1900-gltB W268A $\left(\mathrm{p}-g l t B^{\mathrm{W} 268 \mathrm{~A}} ; g l t B^{\mathrm{W} 268 \mathrm{~A}}\right.$, the tryptophan 268 of GltB was mutated to alanine), pAK1900-gltB ${ }^{\mathrm{D} 301 \mathrm{~A}}\left(\mathrm{p}-g l t B^{\mathrm{D} 301 \mathrm{~A}} ; g l t B^{\mathrm{D} 301 \mathrm{~A}}\right.$, the asparticacid 301 of GltB was mutated to alanine). The primer pair GltB (W34A)-F/GltB (W34A)-R was used to generate $\mathrm{p}-\mathrm{gltB}^{\mathrm{W} 34 \mathrm{~A}}$. The primer pair GltB (K90A)-F/GltB (K90A)-R was used to construct $\mathrm{p}-g l t B^{\mathrm{K} 90 \mathrm{~A}}$. The primer pair GltB (W268A)-F/GltB (W268A)-R was used to generate $\mathrm{p}-g l t B^{\mathrm{W} 268 \mathrm{~A}}$. The primer pair GltB (D301A)-F/GltB (D301A)-R was used to construct $\mathrm{p}-g l t B^{\mathrm{D} 301 \mathrm{~A}}$.

For generating pAK1900-gtrS-YFP (p-gtrS-YFP), primers gtrS-comp-F (with HindIII site) and $g t r S-\mathrm{Y}-\mathrm{R}$ (with BamHI site) were used to perform PCR of the gtrS gene that was meant to fuse with a C-terminal YFP-tag. A $\sim 1.5 \mathrm{~kb}$ PCR product covering $72 \mathrm{bp}$ upstream of $g \operatorname{trS}$ (not including the stop codon) was generated from PAO1 genomic DNA using primers gtrS-comp-F (with HindIII site) and gtrS-Y-R (with BamHI site) and cloned into the pAK1900. A $\sim 0.75 \mathrm{~kb}$ PCR product covering yellow fluorescent protein (YFP) fragment was amplified from plasmid pEYFP (Table S1) using primers YFP-F (with BamHI site) and YFP-R (with KpnI site). The YFP PCR product was digested and then cloned into BamHI/KpnIdigested plasmid p-gtrS, yielding p-gtrS-YFP. To construct pAK1900-gtrS ${ }^{\mathrm{H} 280 \mathrm{~A}}$ (p-gtr $S^{\mathrm{H} 280 \mathrm{~A}}$; $g t r S^{\mathrm{H} 280 \mathrm{~A}}$, the histidine 280 of GtrS was mutated to alanine) and pAK1900-gtrS $S^{\mathrm{H} 280 \mathrm{~A}}-\mathrm{YFP}$ (p-gtrS $\left.{ }^{H 280 A}-Y F P\right)$, the primer pair GtrS (H280A)-F/GtrS (H280A)-R and a QuikChange II site-directed mutagenesis kit (Stratagene, Catalog\#:200518) were used.

To construct pAK1900-gltR-flag (p-gltR-flag), a $\sim 0.7 \mathrm{~kb}$ PCR product covering $38 \mathrm{bp}$ upstream of $g l t R$ (not including the stop codon) was amplified from PAO1 genomic DNA using primers gltR-comp-F (with HindIII site) and gltR-flag-R (with BamHI site).

All constructs were sequenced to ensure that no unwanted mutations resulted.

\subsection{Transposon Mutagenesis}

The $g l t B$ promoter region ( -740 to +20 of the start codon) was amplified by PCR using the primers pro-gltB-F (with XhoI site) and pro-gltB-R (with BamHI site) and cloned into the XhoI and BamHI sites of the mini-CTX-lacZ [34] to generate mini-CTX-gltB-lacZ. The construct was sequenced to ensure that no unwanted mutations resulted. The resulting plasmid was conjugated into wild type PAO1 strain and the construct was integrated into the $a t t B$ site as described previously [32], through a diparental mating using E. coli S17 $\lambda$-pir as the donor. The tetracycline resistance cassette wasdeleted using a flippase (FLP) recombinase encoded on the pFLP2 plasmid [32].

For transposon mutagenesis, the transposon in pBT20 [35] was conjugally transferred by biparental mating into PAO1/mini-gltB-lacZ, following a protocol previously described [36]. Briefly, the donor strain (E. coli SM10- $\lambda$ pir) containing the pBT20 and the recipient $\mathrm{PAO} 1 / \mathrm{mini}-g l t B-l a c Z$ strain were scraped from overnight plates and suspended in $1 \mathrm{~mL}$ of buffer $\left(6.8 \mathrm{~g} \mathrm{Na}_{2} \mathrm{HPO}_{4}, 3 \mathrm{~g} \mathrm{KH}_{2} \mathrm{PO}_{4}, 0.5 \mathrm{~g} \mathrm{NaCl}\right)$. Concentrations of the bacteria in the suspensions were adjusted to $\mathrm{OD}_{600}$ of 40 for the donor and $\mathrm{OD}_{600}$ of 20 for the recipient. Next, each donor and recipient were mixed together and spotted on a LB agar plate and incubated at $37^{\circ} \mathrm{C}$ for $6 \mathrm{~h}$. Mating mixtures were scraped and resuspended in $1 \mathrm{~mL}$ of buffer. Transposon-mutagenized bacteria were selected by plating on PIA plates containing gentamicin at $150 \mu \mathrm{g} / \mathrm{mL}$. A sterile tip was used to pick up individual colonies and dip them into the M8 minimal agar plates (supplying $1.5 \%$ agar and $10 \mathrm{mM}$ glucose) with $20 \mu \mathrm{g} / \mathrm{mL}$ 5-bromo-4-chloro-3-indolyl- $\beta$-D-galactoside (X-gal). Approximately 50,000 colonies were screened for the appearance of blue color. The localization of the Mariner transposon with respect to the P. aeruginosa genome was determined using an established protocol [35].

\subsection{Expression of the Recombinant Proteins in E. coli and their Purification}

The following seven recombinant proteins were expressed in E. coli: (1) 6His-GltB, the N-terminal 6His-tagged GltB; (2) 6His-GltB ${ }^{\text {D301A }}$, a 6 His-GltB variant in which the aspartic acid 301 of GltB was replaced by alanine; (3) 6 His-GtrS ${ }^{L B D}$, the N-terminal 6 His-tagged 
ligand-binding domain of GtrS (residues 29-199); (4) 6His-GltR, the N-terminal 6His-tagged GltR; (5) 6His-GltR ${ }^{\mathrm{D} 56 \mathrm{~A}}$, a 6His-GltR variant in which the aspartic acid 56 of GltR was replaced by alanine; (6) 6 His-Pct ${ }^{\mathrm{LBD}}$, the N-terminal 6 His-tagged ligand-binding domain of PctA (residues 30-278); (7) 6His-PA2788 ${ }^{\mathrm{LBD}}$, the N-terminal 6His-tagged ligand-binding domain of PA2788 (residues 44-179).

For construction of the expression plasmids, the corresponding DNA fragments were amplified by PCR using the primers listed in Supplementary Table S2. Briefly, primer pairs gltB-F/gltB-R (NdeI/XhoI), gtrS-LBD-F/gtrS-LBD-R (NdeI/BamHI), gltR-F/gltR-R (BamHI/XhoI), pctA-LBD-F/pctA-LBD-R (BamHI/HindIII), and pa2788-LBD-F/pa2788-LBD$\mathrm{R}$ (BamHI/HindIII) were, respectively, used to perform PCR of P. aeruginosa PAO1 gltB, $g t r S^{\mathrm{LBD}}, g l t R, p c t A^{\mathrm{LBD}}$ and $p a 2788^{\mathrm{LBD}}$ genes. The PCR products were digested with corresponding restriction endonuclease and cloned into pET28a, yielding pET28a-gltB, pET28a$g t r S^{\mathrm{LBD}}, \mathrm{pET} 28 \mathrm{a}-g l t R, \mathrm{pET} 28 \mathrm{a}-p c t A^{\mathrm{LBD}}$, and $\mathrm{pET} 28 \mathrm{a}-p a 2788^{\mathrm{LBD}}$, respectively. The resulting plasmids allowed the expression of the fusion protein with a $6 \mathrm{His}$-tag at their N-terminus. Colonies were verified by sequencing.

To generate $6 \mathrm{His}-\mathrm{Glt}^{\mathrm{D} 301 \mathrm{~A}}$ and $6 \mathrm{His}-\mathrm{Glt} \mathrm{R}^{\mathrm{D} 56 \mathrm{~A}}$, the pairs of partially overlapping mutagenic primers GltB ${ }^{\mathrm{D} 301 \mathrm{~A}}-\mathrm{F} / \mathrm{GltB}^{\mathrm{D} 301 \mathrm{~A}}-\mathrm{R}$ and $\mathrm{GltR}^{\mathrm{D} 56 \mathrm{~A}}-\mathrm{F} / \mathrm{GltR}^{\mathrm{D} 56 \mathrm{~A}}-\mathrm{R}$ were, respectively, used to amplify the entire plasmid with a high-fidelity DNA polymerase. Then, the template DNA was eliminated by digestion with DpnI. The resulting products were transformed into E. coli DH5 $\alpha$ and colonies were selected on LB supplemented with kanamycin $(50 \mu \mathrm{g} / \mathrm{mL})$. Plasmid from resulting clones was isolated and verified by sequencing.

The protein was expressed in E. coli strain BL21 star (DE3) and purifications were performed as previously described [36,37]. Briefly, bacteria were grown at $37^{\circ} \mathrm{C}$ overnight in $10 \mathrm{~mL}$ of LB medium with shaking $(250 \mathrm{rpm})$. The cultures were transferred into $1 \mathrm{~L}$ of LB medium supplemented with kanamycin $(50 \mu \mathrm{g} / \mathrm{mL})$ incubated at $37{ }^{\circ} \mathrm{C}$ with shaking (200 rpm) until the $\mathrm{OD}_{600}$ reached 0.6 , and then isopropyl-1-thio- $\beta$-d-galactopyranoside (IPTG) was added to a final concentration of $1 \mathrm{mM}$. Then, the cultures were incubated overnight at $16^{\circ} \mathrm{C}$ with shaking $(200 \mathrm{rpm})$. The cultures were harvested by centrifugation at $8000 \mathrm{rpm}$ for $8 \mathrm{~min}$ and then cells were stored at $-80{ }^{\circ} \mathrm{C}$.

The cells were suspended in $40 \mathrm{~mL}$ of buffer A [50 mM Tris- $\mathrm{HCl}, \mathrm{PH} 7.5,300 \mathrm{mM}$ $\mathrm{NaCl}, 10 \mathrm{mM}$ imidazole, $1 \mathrm{mM}$ dithiothreitol (DTT)] and lysed at $4{ }^{\circ} \mathrm{C}$ by sonication to produce lysates containing all of the cell contents. The whole cell fraction was subjected to centrifugation at $4^{\circ} \mathrm{C}$ at $12,000 \mathrm{rpm}$ for $25 \mathrm{~min}$ to remove insoluble material and the membrane fraction. The resulting supernatant was loaded onto a $5 \mathrm{~mL}$ His-Trap column (Code\#: 17-5247-01, GE Healthcare), equilibrated with buffer A and eluted with a 0-100\% gradient of buffer $\mathrm{B}(50 \mathrm{mM}$ Tris- $\mathrm{HCl}, \mathrm{pH} 7.5,300 \mathrm{mM} \mathrm{NaCl}, 500 \mathrm{mM}$ imidazole, $1 \mathrm{mM}$ DTT). After that, the fractions containing 6 His-GltB, 6 His-GtrS ${ }^{\mathrm{LBD}}$, 6 His-GltR, 6 His-PctA $^{\text {LBD }}$, 6 HisPA2788 ${ }^{\mathrm{LBD}}, 6 \mathrm{His}-\mathrm{GltB}^{\mathrm{D} 301 \mathrm{~A}}$ or $6 \mathrm{His}^{-G l t R^{\mathrm{D} 56 \mathrm{~A}}}$ were collected and loaded onto the HiTrap Desalting $5 \times 5 \mathrm{~mL}$ (Sephadex G-25 S) (Code\#: 17-1408-01, GE Healthcare) and eluted with buffer R (50 mM Tris-HCl, PH 7.5, $300 \mathrm{mM} \mathrm{NaCl}, 1 \mathrm{mM}$ DTT) to remove the imidazole. The purified protein was $>90 \%$ pure as estimated by a $12 \%$ (wt/vol) SDS/PAGE gel. Protein concentrations were determined using the Nanodrop 2000 by A280.

\subsection{Monitoring Gene Expression by Lux-Based Reporters}

The plasmid mini-CTX-lux (carrying a promoterless $l u x C D A B E$ reporter gene cluster, Table S1) [34] was used to construct promoter-luxCDABE reporter fusions gltB-lux. The glt $B$ promoter region $(-740$ to +20 of the start codon) was amplified by PCR using the primers pro-gltB-F (with XhoI site) and pro-gltB-R (with BamHI site) and cloned into the XhoI and BamHI sites of the mini-CTX-lux (Table S1) to generate mini-CTX-gltB-lux. The resulting plasmid was conjugated into $P$. aeruginosa strains and the construct was integrated into the attB site as described previously [32] through a diparental mating using E. coli S17 $\lambda$-pir as the donor.

A similar method was used to generate gntR-lux, ptxS-lux, glk-lux, edd-lux, toxA-lux, opgG-lux, and ctpH-lux. The gntR promoter region (-466 to +31 of the start codon) was 
amplified by PCR using the primers pro-gntR-F (with HindIII site) and pro-gntR-R (with BamHI site). The $p t x S$ promoter region ( -749 to +27 of the start codon) was amplified by PCR using the primers pro-ptxS-F (with HindIII site) and pro-ptxS-R (with EcoRI site). The glk promoter region ( -730 to +56 of the start codon) was amplified by PCR using the primers pro-glk-F (with HindIII site) and pro-glk-R (with BamHI site). The edd promoter region ( -520 to +26 of the start codon) was amplified by PCR using the primers pro-edd-F (with HindIII site) and pro-edd-R (with BamHI site). The toxA promoter region ( -980 to -5 of the start codon) was amplified by PCR using the primers pro-toxA-F (with HindIII site) and pro-toxA-R (with BamHI site). The opgG promoter region ( -493 to +20 of the start codon) was amplified by PCR using the primers pro-opgG-F (with HindIII site) and proopgG-R (with BamHI site). The $c t p H$ promoter region ( -229 to +99 of the start codon) was amplified by PCR using the primers pro-ctpH-F (with HindIII site) and pro-ctpH-R (with $B a m H I$ site). To construct the plasmid gltB-D-lux (gltB-lux which lacking the conserved GltR-binding site, $5^{\prime}$-GTGACAAA- $\left.3^{\prime}\right)$, the primer pair pro-gltB-D-F/pro-gltB- $D-\mathrm{R}$ and a QuikChange II site-directed mutagenesis kit (Stratagene, Catalog\#:200518) were used. In PAO1 and its derivatives, parts of the mini-CTX-lux vector containing the tetracycline resistance cassette were deleted using a flippase (FLP) recombinase encoded on the pFLP2 plasmid. All the promoters are oriented in the same direction as luxCDABE, and constructs were sequenced to ensure that no unwanted mutations resulted.

Unless noted otherwise, the expression of promoter fusion genes was measured in a 96-well black-wall clear-bottom plate (Corning incorporated, Costar, Code\#:3603). Briefly, $P$. aeruginosa strains were grown in M8 minimal medium at $37^{\circ} \mathrm{C}$ overnight with shaking at $250 \mathrm{rpm}$, then diluted 50 -fold in $1 \mathrm{~mL}$ of fresh M8 minimal medium supplemented with or without $10 \mathrm{mM}$ glucose. A $150 \mu \mathrm{L}$ volume of the sample was added to the wells and a $80 \mu \mathrm{L}$ volume of filter-sterilized mineral oil was further added in order to prevent evaporation during the assay. Promoter activities were measured as counts per second (CPS) of light production with a Synergy 2 Multi-Mode Microplate Reader as described previously [36,38]. Relative light units were calculated by normalizing CPS to $\mathrm{OD}_{600}$.

The expression of promoter fusion genes was also carried out using a tube culture method, as indicated. Strains were grown in M9 minimal medium [31] in the presence or absence of $5 \mathrm{mM}$ effector (glucose, gluconate or 2-ketogluconate), as indicated. Overnight cultures were diluted to a turbidity of 0.01 in the fresh M9 minimal medium supplemented with or without effector. The diluted cultures were grown in a $20 \mathrm{~mL}$ tube with a tube volume-to-medium volume ratio of $5: 1$ and growth was continued at $37^{\circ} \mathrm{C}$ with shaking ( $250 \mathrm{rpm}$ ) for $8 \mathrm{~h}$, a $100 \mu \mathrm{L}$ volume of the sample was added to the well of a 96-well blackwall clear-bottom plate (Corning incorporated, Costar, Code\#: 3603) in order to measure the CPS of light production. Each sample was tested in triplicate. Relative light units were calculated by normalizing CPS to $\mathrm{OD}_{600}$.

\subsection{Bacterial Growth Assays}

P. aeruginosa strains were grown in LB supplemented with carbenicillin $(100 \mu \mathrm{g} / \mathrm{mL})$ at $37^{\circ} \mathrm{C}$ overnight with shaking at $250 \mathrm{rpm}$. Overnight cultures were washed thrice. Then, the cultures were diluted 100 -fold in $1 \mathrm{~mL}$ of fresh minimal medium (MM) supplemented with $10 \mathrm{mM}$ glucose as the sole carbon source. After that, a $150 \mu \mathrm{L}$ volume of the sample was added to the wells and an $80 \mu \mathrm{L}$ volume of filter-sterilized mineral oil was added in order to prevent evaporation during the assay. The absorption of $\mathrm{OD}_{600}$ was detected at different time points at $37^{\circ} \mathrm{C}$ by a Synergy 2 Multi-Mode Microplate Reader as described previously $[36,38]$. A similar experimental procedure was used to detect bacterial growth on $10 \mathrm{mM}$ gluconate or 2-ketogluconate $(2-\mathrm{KG})$ as the sole carbon source.

\subsection{Thermal Shift Assays}

Thermal Shift assays were performed as previously described [39] with some modifications. Reaction mixtures were prepared by $5 \mu \mathrm{M}$ purified proteins and molecule to a desired concentration into the buffer A ( $50 \mathrm{mM}$ Tris- $\mathrm{HCl}, \mathrm{PH} 7.5,300 \mathrm{mM} \mathrm{NaCl}, 10 \mathrm{mM}$ 
imidazole, $1 \mathrm{mM}$ DTT) and $2 \mu \mathrm{L}$ of $50 \times$ Sypro Orange (Invitrogen, Lot: 1873204) was added to the mixture to yield a final reaction volume of $20 \mu \mathrm{L}$. The 96 -well PCR plates were sealed with optical seal, shaken, and centrifuged after the protein and the molecule were added. Thermal scanning $\left(25\right.$ to $80^{\circ} \mathrm{C}$ at $0.5^{\circ} \mathrm{C} / \mathrm{min}$ ) was performed using a Bio-Rad 96 Well Real-Time PCR System. Fluorescence signals of all samples have been normalized to relative values of $0 \%$ (the lowest fluorescence signal) and $100 \%$ (the highest fluorescence signal), respectively. A negative control lacking molecule was present on each assay plate. All assays were performed in triplicate.

\subsection{Isothermal Titration Calorimetry (ITC)}

ITC was carried out according to a previous study with some modifications [40] using ITC200 (Malvern) at $25{ }^{\circ} \mathrm{C}$ with a constant stirring rate at $750 \mathrm{rpm}$. GltB was diluted in buffer (50 mM Tris- $\mathrm{HCl}, \mathrm{PH} 7.5,300 \mathrm{mM} \mathrm{NaCl})$ and glucose was dissolved in the same buffer. The GltB protein solution $(370 \mu \mathrm{L}$ at $17 \mu \mathrm{M})$ was prepared, and then degassed and injected into the sample cell, followed by the titration of glucose solution $(220 \mu \mathrm{L}$ at $200 \mu \mathrm{M})$. The ligand was injected twenty times ( $1 \mu \mathrm{L}$ for injection 1 and $2 \mu \mathrm{L}$ for injections $2-20)$, with 120 s intervals between injections. Raw titration data were concentration-normalized and corrected for dilution effects prior to analysis using the "One-binding site model" of the MicroCal version of ORIGIN. The parameters $\Delta H$ (reaction enthalpy), $K_{\mathrm{A}}$ (binding constant, $K_{\mathrm{A}}=1 / K_{\mathrm{D}}$ ) and $\mathrm{n}$ (reaction stoichiometry) were determined from the curve fit. The changes in free energy $(\Delta G)$ and entropy $(\Delta S)$ were calculated from the values of $K_{\mathrm{A}}$ and $\Delta H$ with the equation: $\Delta G=-R T \ln K_{\mathrm{A}}=\Delta H-T \Delta S$, where $\mathrm{R}$ is the universal molar gas constant and $\mathrm{T}$ is the absolute temperature.

\subsection{Phosphorylation of GltR and its Variants by Acetyl Phosphate}

Phosphorylation of 6 His-GltR by acetyl phosphate was detected with the Pro-Q Diamond phosphorylation gel stain as described by the manufacturer (Invitrogen). Purified 6His-GltR $(\sim 2 \mu \mathrm{g})$ or 6 His-GltR ${ }^{\mathrm{D} 56 \mathrm{~A}}(\sim 2 \mu \mathrm{g})$ was added to phosphorylation reaction buffer (10 mM Tris pH 8.0, $5 \mathrm{mM} \mathrm{MgCl} 2,10 \mathrm{mM} \mathrm{KCl}, 1 \mathrm{mM}$ DTT) supplemented with or without $50 \mathrm{mM}$ acetyl phosphate, and the mixtures were incubated at $37^{\circ} \mathrm{C}$ for $30 \mathrm{~min}$. A total of $10 \mu \mathrm{L}$ aliquots were removed following the addition of $2 \mu \mathrm{L} 5 \times$ SDS loading buffer $(50 \mathrm{mM}$ Tris-HCl, pH 6.8, 2\% SDS, 0.1\% bromophenol blue, 1\% mercaptoethanol; $10 \%$ glycerol, $100 \mathrm{mM}$ DTT). The samples were resolved on a $12 \%$ SDS polyacrylamide gel at $4{ }^{\circ} \mathrm{C}$, and then the gel was immersed in the fixing solution (10\% acetic acid, 50\% methanol) for $60 \mathrm{~min}$ and then washed three times with deionized water each for $10 \mathrm{~min}$. Subsequently, the gel was stained with Pro-Q Diamond phosphoprotein gel stain for 60 90 min, followed by washing twice with deionized water each for $5 \mathrm{~min}$. Fluorescent output was recorded using Tanon-5200 multi, according to the manufacturer's recommendation.

\subsection{Chromatin Immunoprecipitation (CHIP) and CHIP-seq Data Analysis}

For generating the plasmid mini-gltR-flag-lacZ, primers pAK1900-mini-F (with XbaI site) and pAK1900-mini-R (with XbaI site) were used. Briefly, a 1 kb PCR product covering the lac promoter of pAK1900 plasmid and the gltR-flag was amplified from p-gltR-flag plasmid (Table S1) DNA. The PCR product was cloned into integrated mini-CTX-lacZ vector [34].

Chromatin immunoprecipitation (CHIP) was performed as previously described [41] with minor changes. The experiments were performed with three biological replicates. Wild type P. aeruginosa PAO1 containing mini-gltR-flag-lacZ (Table S1) was cultured in M8 minimal medium supplemented with $10 \mathrm{mM}$ glucose overnight at $37{ }^{\circ} \mathrm{C}$ with shaking (250 rpm), diluted 10-fold in fresh M8 minimal medium supplemented with $10 \mathrm{mM}$ glucose. The diluted cultures were grown in a $1 \mathrm{~L}$ Erlenmeyer flask with a flask volume-to-medium ratio of $5: 1$ at $37^{\circ} \mathrm{C}$ with shaking $(250 \mathrm{rpm})$. After incubated at $37^{\circ} \mathrm{C}$ for $6 \mathrm{~h}\left(\mathrm{OD}_{600} \approx 0.5\right)$, cultures were treated with $1 \%$ formaldehyde for $10 \mathrm{~min}$ at $37^{\circ} \mathrm{C}$ with shaking $(100 \mathrm{rpm})$. Cross-linking was stopped by addition of glycine to a final concentration of $125 \mathrm{mM}$. The 
$75 \mathrm{~mL}$ cultures were collected by centrifugation, then pellets were washed twice with a Tris buffer $(20 \mathrm{mM}$ Tris- $\mathrm{HCl} \mathrm{pH} 7.5,150 \mathrm{mM} \mathrm{NaCl})$, and then resuspended in $500 \mu \mathrm{L}$ IP buffer [50 mM HEPES-KOH pH 7.5, 150 mM NaCl, 1 mM EDTA, 1\% Triton X-100, 0.1\% SDS, protease inhibitor cocktail (Thermo, Cat\#:78420)] and the DNA was sonicated (Scientz, JY92-IIDN) to shear DNA to an average size of 200-500 bp (10\% total output, 1-second on, 2-second off, for $60 \mathrm{~min}$ on ice). Insoluble cellular debris was removed by centrifugation $\left(12,000 \mathrm{rpm}, 4^{\circ} \mathrm{C}\right)$ for $5 \mathrm{~min}$ and the supernatant was saved. Immunoprecipitation samples were incubated overnight at $4{ }^{\circ} \mathrm{C}$ on a rotating wheel with protein A beads (SmartLifesciences, Cat\#: SA015C), which was incubated with $100 \mu \mathrm{L}$ agarose-conjugated anti-flag antibodies (Cat\#: AGM12165, Aogma) in IP buffer. Input samples without antibody were set up as negative control. Washing, crosslink reversal, and purification of the CHIP DNA were conducted by following previously published protocols [42] with minor changes. Briefly, the beads were then collected and washed once with $1 \mathrm{~mL}$ of IP buffer, once with $1 \mathrm{~mL}$ of IP buffer plus $500 \mathrm{mM} \mathrm{NaCl}$, once with $1 \mathrm{~mL}$ of IP buffer plus $250 \mathrm{mM} \mathrm{LiCl}$, and once with $1 \mathrm{~mL}$ of Tris-EDTA buffer ( $\mathrm{pH} 7.5)$. Immunoprecipitated complexes were eluted from the beads by treatment with $100 \mu \mathrm{L}$ elution buffer (50 mM Tris-HCl pH 7.5, $10 \mathrm{mM}$ EDTA, $1 \% \mathrm{SDS}$ ) at $65^{\circ} \mathrm{C}$ for $20 \mathrm{~min}$. Samples were then treated with Protease $\mathrm{K}$ (TIANGEN) and cross-links were reversed by incubation overnight at $65^{\circ} \mathrm{C}$. Overnight samples were then treated with $50 \mu \mathrm{g}$ RNase A at $37^{\circ} \mathrm{C}$ for $1 \mathrm{~h}$. DNA was extracted twice with phenol-chloroform, precipitated with ethanol at $-80^{\circ} \mathrm{C}$ for $4 \mathrm{~h}$, and then resuspended in $20 \mu \mathrm{L}$ of deionized water.

DNA fragments (200 to $500 \mathrm{bp}$ ) were selected for library construction, and sequencing libraries were prepared using the NEBNext Ultra II DNA Library Prep kit. The final DNA libraries were validated with Agilent 2100 Bioanalyzer using Agilent High Sensitivity DNA Kit, then the libraries were sequenced using the HiSeq PE150 system (Illumina) completed by Sangon Biotech (Shanghai, China). CHIP-seq reads were mapped to the P. aeruginosa genomes, using BBMap with two mismatches allowed. Only the uniquely mapped reads were kept for the subsequent analyses. The enriched peaks were identified using MACS14 software (version 1.4.2) [43] and were visualized and screenshots prepared using Integrative Genome Viewer (IGV) (Broad Institute, version 2.4.6). We filtered peaks called by MACS14 by requiring an adjusted score (i.e., $-\log 10 p$-value) of at least 50 in order to ensure that we had a high quality peak annotation, and peaks with a fold enrichment lower than 3 -fold changes were also filtered out. A total of 16 peaks ( $\geq 10$-fold enrichment, in average) were used to define the GltR-binding motif using the MEME tool [44]. Annotation of the peaks was performed using the SnpEff (4.3s) (http:/ / www.htslib.org/, accessed on 1 May 2019). The CHIP-seq data files have been deposited in NCBI's (National Center of Biotechnology Information) Gene Expression Omnibus (GEO) and can be accessed through GEO Series accession number GSE153848, with the following BioSample accession numbers: SAMN15457028 to SAMN15457031.

\subsection{Electrophoretic Mobility Shift Assay (EMSA)}

EMSA experiments were performed as previously described [38] with some modifications. Briefly, reactions were conducted in a mixture containing DNA probe (40 ng), various amounts of purified $6 \mathrm{His}-\mathrm{GltR}$ or $6 \mathrm{His}-\mathrm{GltR}^{\mathrm{D} 56 \mathrm{~A}}$, followed by the addition of binding buffer (10 mM Tris-Cl, pH 7.8, $1 \mathrm{mM}$ DTT, $10 \%$ glycerol, $5 \mathrm{mM} \mathrm{MgCl}_{2}, 10 \mathrm{mM} \mathrm{KCl}$ ) up to $15 \mu \mathrm{L}$. The mixtures were incubated at $37^{\circ} \mathrm{C}$ for $30 \mathrm{~min}$. When indicated, $50 \mathrm{mM}$ acetyl phosphate was added to the solution. Native polyacrylamide gel $(6 \%)$ was run in $0.5 \times$ TBE buffer at $85 \mathrm{~V}$ at $4{ }^{\circ} \mathrm{C}$. The gel was stained with GelRed nucleic acid staining solution (Biotium) for $5 \mathrm{~min}$, and then the DNA bands were visualized by gel exposure to $260 \mathrm{~nm}$ UV light.

DNA probes were amplified by PCR using P. aeruginosa PAO1 genomic DNA as templates, and the set of primer pairs indicated in Supplementary Table S2. All PCR products were purified by using a QIAquick gel purification kit (QIAGEN). For $g l t B-p$, a $302 \mathrm{bp}$ DNA fragment covering the promoter region of gltB (from nucleotide -266 to nucleotide +36 relative to the start codon of $g l t B$ ) was amplified with primer pair $g l t B-F$ 
(EMSA)/gltB-R (EMSA). For opgG-p, a 513 bp DNA fragment covering the promoter region of opgG (from nucleotide -493 to nucleotide +20 relative to the start codon of opgG) was amplified with primer pair opgG-F (EMSA)/opgG-R (EMSA). For $c t p H-p$, a 328 bp DNA fragment covering the promoter region of $c t p H$ (from nucleotide -229 to nucleotide +99 relative to the start codon of $c t p H)$ was amplified with primer pair $c t p H-F$ (EMSA) $/ c t p H-$ $\mathrm{R}$ (EMSA). For the control DNA fragment used in the EMSAs, exsA- $p$ is a 376 bp DNA fragment amplified from the promoter region exs $A$ (from nucleotide -343 to nucleotide +33 relative to the start codon of exs $A$ ) with primer pair exs $A-\mathrm{F}$ (EMSA)/ exs A-R (EMSA).

\subsection{Dye Primer-Based DNase I Foot-Printing Assay}

The published DNase I footprint protocol was modified [45]. Briefly, reactions were conducted in a mixture containing 6-carboxyfluorescein(6-FAM)-labeled promoter DNA (300 ng), indicated concentration of purified 6His-GltR, followed by the addition of binding buffer (10 mM Tris-Cl, pH 7.8, 1 mM DTT, 10\% glycerol, $5 \mathrm{mM} \mathrm{MgCl}$, $10 \mathrm{mM} \mathrm{KCl,} 50 \mathrm{mM}$ acetyl phosphate) up to $50 \mu \mathrm{L}$. The mixtures were incubated at $37^{\circ} \mathrm{C}$ for $30 \mathrm{~min} .0 .05$ unit of DNase I (Promega Biotech Co., Ltd, Cat\#:137017) was added to the reaction mixture and incubated for 1 10 min. The digestion was terminated by adding $200 \mu \mathrm{L}$ phenol-choroformisoamyl (25:24:1) and $145 \mu \mathrm{L}$ deionized water. The digested DNA fragments were isolated by ethanol precipitation. A total of $5 \mu \mathrm{L}$ of digested DNA was mixed with $4.9 \mu \mathrm{L}$ of HiDi formamide and $0.1 \mu \mathrm{L}$ of GeneScan-500 LIZ size standards (Applied Biosystems). The sample was detected by a 3730XL DNA analyzer, and the result was analyzed with GeneMapper software (Applied Biosystems). The dye primer based Thermo SequenaseTM Dye Primer Manual Cycle Sequencing Kit (Thermo, Lot:4313199) was used in order to more precisely determine the sequences of the GltR-protection region after the capillary electrophoresis results of the reactions were aligned, and the corresponding label-free promoter DNA fragment was used as template for DNA sequencing. Electropherograms were then analyzed with GeneMarker v1.8 (Applied Biosystems).

DNA probes were amplified by PCR using $P$. aeruginosa PAO1 genomic DNA as templates, and the set of primer pairs indicated in Supplementary Table S2. For the DNase I footprinting assay of $g l t B$, a 302 bp FAM (carboxyfluorescein) labeled promoter DNA (nucleotide -266 to nucleotide +36 relative to the start codon of $g l t B$ ) was generated using the primer pair $g l t B-F$ (EMSA)-FAM/gltB-R (EMSA). For the DNase I footprinting assay of opgG, a 513 bp FAM (carboxyfluorescein) labeled promoter DNA (nucleotide -493 to nucleotide +20 relative to the start codon of $o p g G$ ) was generated using the primer pair opgG-F (EMSA)-FAM/opgG-R (EMSA). For the DNase I footprinting assay of ctpH, a 328 bp FAM (carboxyfluorescein) labeled promoter DNA (nucleotide -229 to nucleotide +99 relative to the start codon of $c t p H$ ) was generated using the primer pair $c t p H$-F (EMSA)FAM $/ c t p H-R$ (EMSA). PCR products were purified by with QIA quick gel purification kit (QIAGEN).

\subsection{Western Blotting}

Strains were grown in M8 minimal medium in the presence or absence of $10 \mathrm{mM}$ glucose at $37^{\circ} \mathrm{C}$ overnight with shaking at $250 \mathrm{rpm}$, diluted 25-fold in fresh M8 minimal medium supplemented with or without $10 \mathrm{mM}$ glucose. The diluted cultures were grown in a $20 \mathrm{~mL}$ tube with a tube volume-to-medium volume ratio of 5:1, shaking with $250 \mathrm{rpm}$ at $37^{\circ} \mathrm{C}$ for about $6 \mathrm{~h}\left(\mathrm{OD}_{600} \approx 0.4\right)$. Cell cultures were harvested to $\mathrm{OD}_{600} 0.8$ by centrifugation at 14,000 rpm for $15 \mathrm{~min}$ and resuspended in $80 \mu \mathrm{L}$ deionized water and $20 \mu \mathrm{L} 5 \times$ SDS-PAGE loading buffer [ $50 \mathrm{mM}$ Tris-HCl, pH 6.8, 2\% SDS, 0.1\% bromophenol blue, 1\% mercaptoethanol, 10\% glycerol, $100 \mathrm{mM}$ dithiothreitol (DTT)] and then heated at $100{ }^{\circ} \mathrm{C}$ for $10 \mathrm{~min}$.

A total of $10 \mu \mathrm{L}$ of loading buffer-treated sample as described above was loaded onto a $12 \%$ SDS polyacrylamide gel. SDS-PAGE was carried out at $80 \mathrm{~V}$ for $15 \mathrm{~min}$ followed by $120 \mathrm{~V}$ for $80 \mathrm{~min}$. Samples resolved on gels were transferred to PVDF (Bio-Rad) membranes through semi-dry transfer assembly (Bio-Rad) for $28 \mathrm{~min}$ at room temperature. 
The membrane was incubated with the primary antibody in 5\% (wt/vol) skim milk at $4{ }^{\circ} \mathrm{C}$ overnight following the blocking step $(15 \mathrm{~mL}$ of $5 \%$ (wt/vol) skim milk) at room temperature for $2 \mathrm{~h}$, and then washed four times at room temperature each for $30 \mathrm{~min}$ in TBST buffer (10 mM Tris- $\mathrm{HCl}$, pH 7.5, $150 \mathrm{mM} \mathrm{NaCl}$, and 0.1\% Tween 20). Then, membranes were incubated with the secondary antibody for $2 \mathrm{~h}$ at room temperature and washed four times each for $30 \mathrm{~min}$ in TBST. The chemiluminescent detection reaction was performed and detected by Tanon-5200 multi, according to the manufacturer's recommendation.

GltB proteins were detected by using a rabbit anti-GltB polyclonal antibody (prepared by immunizing a rabbit with a N-terminal 6His-tagged full-length GltB protein, Sangon Biotech Co., Ltd.) at 1:2000 followed by a secondary, an anti-rabbit IgG antibody conjugated to horseradish peroxidase (HRP) (Code\#: NA934, GE Healthcare) at 1:5000. GtrS-YFP proteins were detected by using a rabbit anti-GFP antibody (KleanAB, \#P100009) at 1:2000 followed by a secondary, sheep anti-rabbit IgG antibody conjugated to horseradish peroxidase (HRP) (Code\#: NA934, GE Healthcare) at 1:5000. GltR-Flag proteins were detected by using a mouse anti-Flag monoclonal antibody (Cat\#: AGM12165, Aogma) at 1:2000 followed by a secondary, sheep anti-mouse IgG antibody conjugated to horseradish peroxidase (HRP) (Code\#: NA931, GE Healthcare) at 1:5000. For detection of RNAP protein, anti-RNAP (Neoclone, \#WP003) antibody at 1:2000 and anti-mouse IgG antibody conjugated to horseradish peroxidase (HRP) (Code\#: NA931, GE Healthcare) at 1:5000 were used.

\subsection{Localized Surface Plasmon Resonance}

The interaction of $6 \mathrm{His}-\mathrm{GltB}$ and $6 \mathrm{His}-\mathrm{G} t \mathrm{~S}^{\mathrm{LBD}}$ was analyzed using an OpenSPR localized surface plasmon resonance (Nicoya Lifesciences, Waterloo, Canada). 6His-GtrS ${ }^{\mathrm{LBD}}$ protein was fixed on the $\mathrm{COOH}$ sensor chip by capture-coupling, then 6His-GltB at concentrations of $1000 \mathrm{nM}, 500 \mathrm{nM}, 250 \mathrm{nM}, 125 \mathrm{nM}$ were injected sequentially into the chamber in running buffer $\left(50 \mathrm{mM}\right.$ Tris, $50 \mathrm{mM} \mathrm{NaCl}, \mathrm{pH} \mathrm{7.0)}$ at $25{ }^{\circ} \mathrm{C}$. The binding time and disassociation time were both $375 \mathrm{~s}$, the flowrate was $20 \mu \mathrm{L} / \mathrm{min}$, the chip was regenerated with $0.02 \%$ SDS. A one to one diffusion corrected model was fitted to the wavelength shifts corresponding to the varied drug concentration. The data were retrieved and analyzed with TraceDrawer software (Ridgeview Instruments ab, Sweden). Kinetic parameters were calculated using a global analysis, and the data was fitted to a one to one model.

The similar experimental procedure was used to analyze the interaction of $6 \mathrm{His}-\mathrm{GltB}$ with 6 His-PctA ${ }^{\text {LBD }}$. 6His-GltB protein was fixed on the $\mathrm{COOH}$ sensor chip by capturecoupling, then 6 His-PctA ${ }^{\text {LBD }}$ at concentrations of $1500 \mathrm{nM}, 1200 \mathrm{nM}, 750 \mathrm{nM}, 500 \mathrm{nM}$ were injected sequentially into the chamber in running buffer. The binding time and disassociation time were both $528 \mathrm{~s}$.

For the analysis of the interaction of $6 \mathrm{His}-\mathrm{GltB}$ with $6 \mathrm{His}-\mathrm{PA} 2788^{\mathrm{LBD}}$, $6 \mathrm{His}-\mathrm{GltB}$ protein was fixed on the $\mathrm{COOH}$ sensor chip by capture-coupling, then $6 \mathrm{His}-\mathrm{PA} 2788^{\mathrm{LBD}}$ at concentrations of $500 \mathrm{nM}, 400 \mathrm{nM}, 200 \mathrm{nM}, 100 \mathrm{nM}$ were injected sequentially into the chamber in running buffer. The binding time and disassociation time were both $475 \mathrm{~s}$. The methods used were otherwise identical to those described above.

\subsection{Bacterial Two-Hybrid Analysis}

For monitoring of protein-protein interaction in vivo, the Euromedex bacterial twohybrid (BACTH, for "Bacterial Adenylate Cyclase-based Two-Hybrid") system (Cat No:EUK001) was used $[46,47]$. BACTH relies on reconstitution of activity of the split Bordetella pertussis adenylate cyclase toxin. Reconstitution and thus cAMP production occurs through interaction of candidate proteins fused to the separately encoded T18- and T25-fragments of the B. pertussis toxin. The plasmid-encoded fusion genes are tested in E. coli strain BTH101, which lacks endogenous adenylate cyclase activity. Interaction can be monitored quantitatively by measuring activity of $\beta$-galactosidase, whose synthesis depends on cAMP-CRP. Plasmids pKT25 and pUT18C were used for construction of in- 
frame fusion of the candidate genes to the $3^{\prime}$ ends of the sequences encoding T25 and T18, respectively.

The BACTH plasmid encoding the T18-GltB fusion protein was obtained by amplification of the $g l t B$ gene using primers $g l t B-p U T-F$ (with XbaI site) and $g l t B-p U T-R$ (with KpnI site) indicated in Supplementary Table S2 and subsequent insertion of the PCR-fragment between the XbaI and KpnI sites on the plasmid pUT18C. Note that within the T18-GltB fusion gene, $g l t B$ lacks the first 25 codons encoding the N-terminal signal sequence ( https: / / www.uniprot.org/, accessed on 1 May 2018). Therefore, the GltB sequence fused to T18 corresponds to the mature form of GltB as present in the periplasm. For construction of BACTH plasmid T25-GtrS ${ }^{\mathrm{LBD}}$, the codons 29-199 of $g t r S$ were amplified by PCR of the $g t r S$ gene using the primer pair gtrS-LBD-pKT-F/gtrS-LBD-pKT-R (XbaI/KpnI sites) indicated and inserted between $\mathrm{XbaI}$ and $\mathrm{KpnI}$ sites on the plasmid pKT25. All constructs were sequenced to ensure that no unwanted mutations resulted. BTH101 was co-transformed with the plasmid carrying the T18 and T25 fusion genes.

Transformants were selected using kanamycin $(50 \mu \mathrm{g} / \mathrm{mL})$ and ampicillin $(100 \mu \mathrm{g} / \mathrm{mL})$ on LB agar plates, and were subsequently inoculated onto the M63/maltose agar plates supplemented with kanamycin $(25 \mu \mathrm{g} / \mathrm{mL})$, ampicillin $(50 \mu \mathrm{g} / \mathrm{mL})$, X-Gal $(40 \mu \mathrm{g} / \mathrm{mL})$, and IPTG $(0.5 \mathrm{mM})$, incubated at $30^{\circ} \mathrm{C}$ for up to 6 days. Positive interactions between the target proteins were indicated by the appearance of blue colonies. Protein-protein interaction was also detected by measuring the $\beta$-galactosidase activities in bacteria grown in LB broth containing kanamycin $(50 \mu \mathrm{g} / \mathrm{mL})$, ampicillin $(100 \mu \mathrm{g} / \mathrm{mL})$, and $0.5 \mathrm{mM} \mathrm{IPTG}$ at $30^{\circ} \mathrm{C}$ for $12 \mathrm{~h}$ with shaking at $250 \mathrm{rpm}$, according to the protocol of BACTH system.

\subsection{Co-Immunoprecipitation Coupled with Mass Spectrometric (CoIP-MS)}

P. aeruginosa strains [PAO1/p-gtrS-YFP and $\Delta g l t B / \mathrm{p}-g t r S-\mathrm{YFP}$ (negative control)] were grown in $20 \mathrm{~mL}$ of LB broth containing carbenicillin $(150 \mu \mathrm{g} / \mathrm{mL})$ at $37^{\circ} \mathrm{C}$ overnight with shaking at $250 \mathrm{rpm}$. Overnight cultures were washed twice in $10 \mathrm{~mL}$ of fresh M8 minimal medium and suspended in $20 \mathrm{~mL}$ of fresh M8 minimal medium supplemented with $10 \mathrm{mM}$ glucose, then shaking $\left(250 \mathrm{rpm}\right.$ ) at $37^{\circ} \mathrm{C}$ for $1 \mathrm{~min}$. The $20 \mathrm{~mL}$ cultures were collected by centrifugation (7800 rpm) at $4{ }^{\circ} \mathrm{C}$ for $5 \mathrm{~min}$, washed once in PBS buffer, and then suspended in $1 \mathrm{~mL}$ of lysis buffer provided in the Co-IP kit (Pierce) supplied with $1 \mu \mathrm{L}$ protease inhibitor cocktail (Thermo, Cat\#:78420). The mixture was homogenized by mechanical disruption (Fast Prep FP2400 instrument; Qbiogene) and then the debris was removed by centrifuging at $2300 \mathrm{~g}$ for $9 \mathrm{~min}$ and filtrating through $0.44 \mu \mathrm{m}$ filters. The $700 \mu \mathrm{L}$ clarified lysates were incubated with the resins immobilized with a specific antibody (a rabbit anti-GltB polyclonal antibody) overnight at $4{ }^{\circ} \mathrm{C}$. The bound materials were washed and eluted following the manufacturer's recommendation (Thermo, Cat\#: 26149). The immunocomplexes eluted from the resins by western blot with specific antibodies, as indicated.

Co-IP samples as described above were evaporated by lyophilizer (ThermoFisher, SAVANT SPD111V), then resuspended in $16 \mu \mathrm{L}$ distilled water and mixed with $4 \mu \mathrm{L} 5$ $\times$ SDS-PAGE loading buffer and loaded onto a $12 \%$ polyacrylamide gel. SDS-PAGE was carried out at $80 \mathrm{~V}$ for $15 \mathrm{~min}$ followed by $120 \mathrm{~V}$ for $80 \mathrm{~min}$. The gel was first visualized with Coomassie brilliant blue stain, and then each gel lane was divided into small fractions and digested with trypsin before mass spectrometric analysis. For trypsin digestion, the protein gel was reduced with $20 \mathrm{mM}$ DTT $\left(50 \mathrm{mM} \mathrm{NH}_{4} \mathrm{HCO}_{3}\right)$ at $56^{\circ} \mathrm{C}$ for $30 \mathrm{~min}$ and alkylated with iodoacetamide $\left(50 \mathrm{mM} \mathrm{NH}_{4} \mathrm{HCO}_{3}\right)$ at a final concentration of $100 \mathrm{mM}$ at room temperature for $20 \mathrm{~min}$ in darkness. Then proteins were digested overnight with 1:50 (protein: enzyme, $w / w$ ) trypsin (Promega) at $37^{\circ} \mathrm{C}$.

The proteome analysis was performed on an Orbitrap Q-Exactive HF (Thermo Fisher Scientific) platform connected to an online nanoflow EASY nLC1200 HPLC system (Thermo Fisher Scientific). The tryptic peptides were loaded onto $15 \mathrm{~cm}$ columns packed in-house with C18 $1.9 \mu \mathrm{m}$ ReproSil particles (Dr. Maisch $\mathrm{GmbH}$ ) and separated with a 60-min gradient at a flow rate of $300 \mathrm{~nL} / \mathrm{min}$. A homemade column oven maintained the column 
temperature at $50{ }^{\circ} \mathrm{C}$. A data-dependent acquisition MS method was used, in which one full scan $(350-1500 \mathrm{~m} / \mathrm{z}, \mathrm{R}=70,000$ at $200 \mathrm{~m} / \mathrm{z})$ at a target of $3 \mathrm{e} 6$ ions was first performed, followed by top 15 data-dependent MS/MS scans with higher-energy collisional dissociation (HCD) at a resolution of 17,500 at $200 \mathrm{~m} / \mathrm{z}$. Other instrument parameters were set as follows: $27 \%$ normalized collision energy (NCE), 1e3 AGC target, $100 \mathrm{~ms}$ maximum injection time, $2.0 \mathrm{~m} / \mathrm{z}$ isolation window. Raw mass spectrometry data were processed using MaxQuant version 1.6.0.1 [48] against the P. aeruginosa database, with a false-discovery rate (FDR) $<0.01$ at the level of proteins and peptides. Carbamidomethyl (C) was selected as a fixed modification, oxidized methionine $(\mathrm{M})$ and acetylation (protein $\mathrm{N}$ term) as variable modifications. Control sample was also analyzed in parallel to distinguish the background proteins. After excluding the background interfering proteins, the rest of proteins were identified as potential GltB interacting protein. The mass spectrometry proteomics data have been deposited to the ProteomeXchange Consortium via the PRIDE partner repository with the dataset identifier PXD020213.

\subsection{Drosophila Melanogaster Infection Assays}

Drosophila infection was adapted from the fly needle pricking assay according to the protocol as previously described $[49,50]$. All P. aeruginosa strains were grown in PB medium at $37{ }^{\circ} \mathrm{C}$ overnight with shaking at $250 \mathrm{rpm}$, diluted 100-fold in fresh PB medium. Subsequently, the diluted cultures were grown in a $20-\mathrm{mL}$ tube with a tube volume-tomedium ratio of $5: 1$ at $37{ }^{\circ} \mathrm{C}$ with shaking $(250 \mathrm{rpm})$. After incubation for $3 \mathrm{~h}$, bacteria were harvested by centrifugation, washed twice and suspended in PBS buffer ( $\mathrm{NaCl} 8 \mathrm{~g}$, $\mathrm{KCl} 0.2 \mathrm{~g}, \mathrm{Na}_{2} \mathrm{HPO}_{4} 1.44 \mathrm{~g}, \mathrm{KH}_{2} \mathrm{PO}_{4} 0.24 \mathrm{~g}$, per liter) and then diluted the $\mathrm{OD}_{600}$ to 0.8 . The dorsal side of the thorax of carbon dioxide-anesthetized male flies ( $\sim 5$ days old) was pricked with a sterilized tungsten needle dipped in the appropriate bacterial suspension or PBS buffer. The pricked flies were grown in the fly-food vial, kept at $25{ }^{\circ} \mathrm{C}$ and $65 \%$ humidity. Fly survival was counted and survival curves were processed with GraphPad Prism (GraphPad Software, Inc., San Diego, CA, USA) to perform a statistical log-rank (Mantel-Cox).

\subsection{Mouse Model of Acute Pneumonia}

P. aeruginosa strains were grown in $\mathrm{PB}$ medium at $37^{\circ} \mathrm{C}$ overnight with shaking (250 rpm), diluted 100-fold in fresh PB medium. The diluted cultures were grown in a $100 \mathrm{~mL}$ Erlenmeyer flask with a flask volume-to-medium ratio of $5: 1$ at $37^{\circ} \mathrm{C}$ with shaking $(250 \mathrm{rpm})$. After incubated at $37^{\circ} \mathrm{C}$ for $3 \mathrm{~h}$ until the cultures reached $\mathrm{OD}_{600} 0.8$. Bacteria were collected by centrifugation, washed and suspended in PBS buffer. Mouse infections were carried out as described previously [38], using 8-week-old female C57BL/6J mice. Mice were anaesthetized with pentobarbital sodium (intraperitoneal injection) and intranasally infected with $4 \times 10^{8} \mathrm{CFU}$ of each bacterial isolate. After that, animals were sacrificed $18 \mathrm{~h}$ post infection. Lungs were aseptically removed and homogenized in PBS plus $0.1 \%$ Triton $\mathrm{X}-100$ in order to obtain single-cell suspensions. Serial dilutions of each organ were plated on Pseudomonas isolation agar (PIA) plates. Bacterial burden per organ was calculated and is expressed as a ratio of the inoculum delivered per animal. Statistical analysis (the Mann-Whitney test) was performed using GraphPad Prism.

\section{Results}

\subsection{GtrS-GltR Is Required for Glucose Utilization in Gcd-Deficient P. aeruginosa Strain}

To examine the role of GtrS-GltR TCS in glucose utilization, we deleted the gtrS-gltR locus encoding the GtrS-GltR TCS in the P. aeruginosa reference strain PAO1, yielding $\Delta g t r S-g l t R$, and monitored bacterial growth in a chemically defined minimal medium (MM) amended with glucose as the sole carbon source. The $\Delta g t r S-g l t R$ mutant grew with a similar kinetic to the wild type (WT) PAO1 strain (Figure 1B), indicating that the GtrS-GltR TCS is not essential for glucose utilization by P. aeruginosa PAO1. 


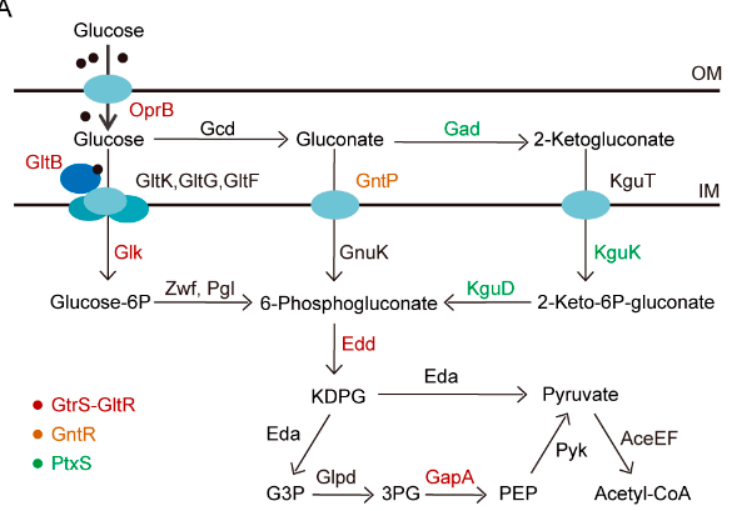

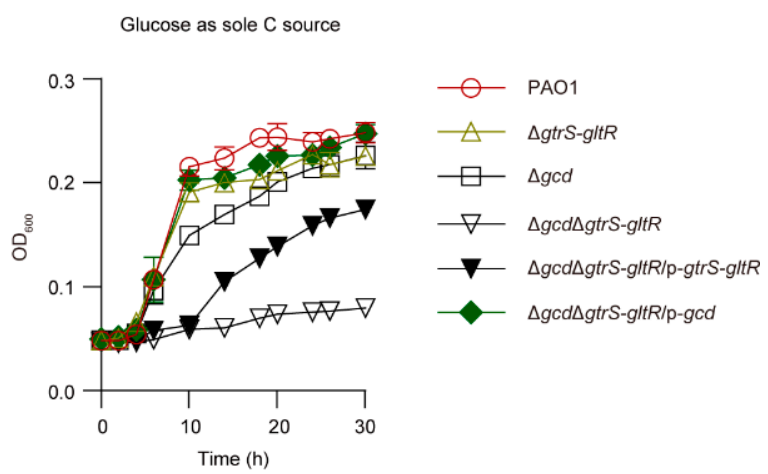

Figure 1. Proposal pathways of glucose metabolism and bacterial growth assays. (A) Schematic view of predicted glucose utilization and metabolism pathways in P. aeruginosa inferred from previous studies [23,51]. Proteins are shown in different colors according to the regulators (e.g., GtrS-GltR, GntR, and PtxS) that participate in their transcriptional regulation $[25,26,52]$. OM, outer membrane; IM, inner membrane; OprB, glucose porin; GltB, periplasmic glucose-binding protein [53-55]; GltK, ATP-binding component of ABC transporter; GltG and GltF, permease of ABC sugar transporter; GntP, gluconate permease; KguT, 2-ketogluconate (2-KG) transporter; Gcd, glucose dehydrogenase; Gad, gluconate dehydrogenase; Glk, glucokinase; GnuK, gluconokinase; KguK, 2-KG kinase; Zwf, glucose-6-phosphate 1-dehydrogenase; Pgl, 6-phosphogluconolactonase; KguD, 2-KG reductase; Edd, phosphogluconate dehydratase; Eda, 2-keto-3-deoxy gluconate aldolase; Glpd, glycerol-3-phosphate dehydrogenase; GapA, glyceraldehyde-3-phosphate dehydrogenase; Pyk, pyruvate kinase; AceEF, pyruvate dehydrogenase. KDPG, 2-keto-3-deoxy-6-phosphogluconate; G3P, glyceraldehyde-3P; 3PG, 3-phosphoglycerate; PEP, phosphoenolpyruvate. (B) The growth curve of P.aeruginosa strains cultured in 96-well plates containing minimal medium (MM) supplemented with $10 \mathrm{mM}$ glucose as the sole carbon source. PAO1, $\Delta g t r S-g l t R$, $\Delta g c d$, and $\Delta g c d \Delta g t r S-g l t R$ harbor an empty pAK1900 vector as control; p-gtrS-gltR denotes the pAK1900-gtrS-gltR plasmid; p-gcd denotes the pAK1900-gcd plasmid. $\mathrm{OD}_{600}$, an optical density at $600 \mathrm{~nm}$. Data from $\mathrm{n}=3$ biological replicates reported as mean $\pm \mathrm{SD}$.

Like gtrS-gltR deletion, the loss of gcd encoding membrane-bound glucose dehydrogenase $(\mathrm{Gcd})$, which catalyzes the periplasmic oxidation of glucose (Figure 1A), has no obvious effect on the ability of P. aeruginosa PAO1 to use glucose as its sole source of carbon for growth (Figure 1B). This observation suggests that the oxidative pathway of glucose degradation (Figure 1A) is not required for glucose utilization by P. aeruginosa PAO1 as well. However, the growth of $\Delta g c d \Delta g t r S$ - $g l t R$ triple mutant strain lacking both $g c d$ and gtrS-gltR on glucose used as the sole carbon source was abolished (Figure 1B), although growth on either gluconate or 2-KG was sustained (Figure S1A,B). The growth defect was restored when the $\Delta g c d \Delta g t r S-g l t R$ was transformed with a plasmid that expressed either gtrS-gltR or $g c d$ (Figure 1B), indicating that GtrS-GltR TCS modulates glucose utilization independently of Gcd, and vice versa. These results suggest that GtrS-GltR is essential for glucose utilization in P. aeruginosa strain when Gcd is absent, which also support the notion that in aerobically grown Pseudomonas species extracellular glucose can be catabolized by either the phosphorylative pathway or the oxidative pathway (Figure 1A).

\subsection{GtrS-GltR Positively Regulates the gltBFGK-oprB Operon}

Because $g l t R$ and $g l t B$, the first gene of the $g l t B F G K-o p r B$ operon involved in glucose uptake, are both essential for glucose transport activity in P. aeruginosa [27,53], we reasoned that GtrS-GltR TCS may activate gltBFGK-oprB operon in response to glucose. Using promoter-fusion analysis, we found that in the absence of glucose the promoter activity of $g l t B$ (i.e., $g l t B-l u x$ ) was low, and it was not obviously affected by the deletion of $g t r S$ - $g l t R$ locus (- Glucose in Figure 2A). In the presence of glucose, the expression level of gltB-lux in WT PAO1 was approximately 64.5 -fold higher than in the absence of glucose (Figure $2 \mathrm{~A})$. However, the addition of glucose failed to increase the expression of gltB-lux in the gtrS-gltR deletion mutant $(\triangle g t r S-g l t R)$, although it did this for the complemented strain $(\Delta g t r S-g l t R / \mathrm{p}-g t r S-g l t R)$ (Figure 2A). Moreover, we found that deletion of $g t r S$, which 
encodes the SK of the GtrS-GltR TCS, completely abolished the glucose-induced gltB-lux (Figure 2A). These data suggest that GtrS-GltR TCS is required for the transcription of gltBFGK-oprB operon in response to glucose. Furthermore, we observed that glucose failed to increase the expression of $g l t B-l u x$ in the $\Delta g t r S-g l t R$ mutant complemented with a plasmid carrying the functional gtrS (i.e., p-gtrS) (Figure 2A), which indicates that $g l t R$ is required for the glucose-induced expression of gltB-lux.

A
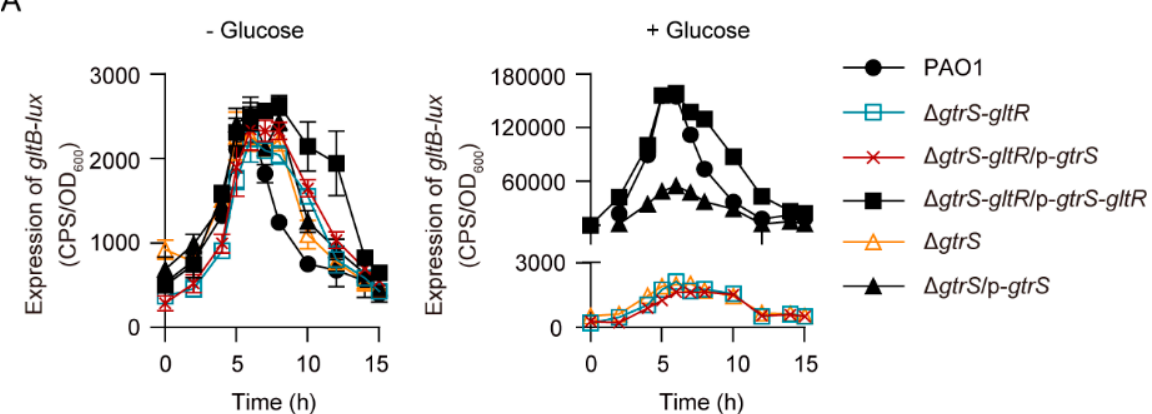

B
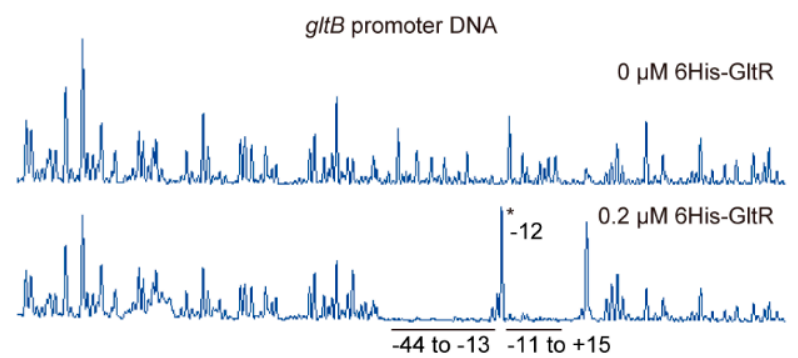

-44 5'- CAATGTAACCGCTCCGTGACAAACCC GGATCGCTTCGTTACCCGCGACGCGGA -3' +15

C

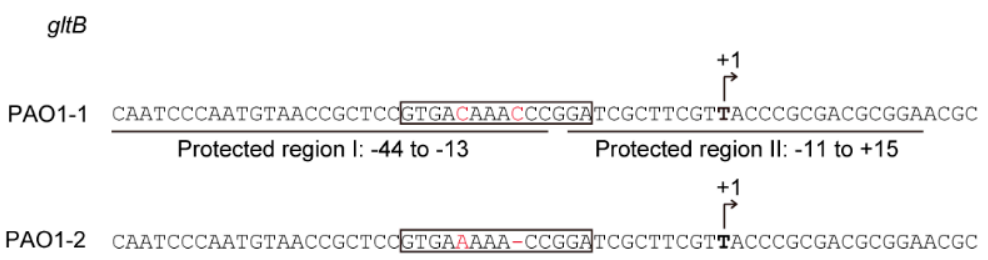

Figure 2. GtrS-GltR TCS positively controls the promoter activity of gltB. (A) The expression of gltB-lux in P. aeruginosa strains cultured in 96-well plates containing M8-MM supplemented with $(+)$ or without (-) $10 \mathrm{mM}$ glucose. CPS, counts per second. $\mathrm{OD}_{600}$, an optical density at $600 \mathrm{~nm}$. Data from $\mathrm{n}=3$ biological replicates reported as mean $\pm \mathrm{SD}$. PAO1, $\Delta g t r S-g l t R$, and $\Delta g t r S$ harbor an empty pAK1900 vector as control; p-gtrS-gltR denotes the pAK1900-gtrS-gltR plasmid; p-gtrS denotes the pAK1900-gtrS plasmid. (B) Electropherograms show the protection pattern of the $g l t B$ promoter DNA after digestion with DNase I following incubation in the absence or presence of 6 His-GltR. The protected region (relative to the transcriptional initiation site of $g l t B$ ) was underlined, and the asterisk indicates the DNase I hypersensitivity site. The sequence covering the two GltR-protected regions in the $g l t B$ promoter DNA $(g l t B-p)$ are shown. The conserved GltR-binding site inferred from previous study by Daddaoua et al. (2014) [26] is in bold. (C) Analysis of the DNA sequence of gltB promoter in P. aeruginosa strains. PAO1-1, partial gltB promoter sequence of the PAO1 strain with published reference sequence [13] or that of our laboratory PAO1 strain [19]; PAO1-2, the partial gltB promoter sequence of the PAO1 strain used by Daddaoua et al. (2014) [26]. Boxes highlight the reported GltR-binding sites Daddaoua et al. (2014) [26] and the differences between PAO1-1 and PAO1-2 are shown with red letters. The transcriptional start sites inferred from Daddaoua et al. (2014) [26] are indicated by arrows and bold letters. 
Like some other RRs [38,56], the N-terminally 6His-tagged GltR protein (i.e., 6HisGltR) can be phosphorylated by the low molecular weight phosphodonor acetyl phosphate (Figure S2A,B). The 6His-GltR mutant (i.e., $6 \mathrm{His}-\mathrm{GltR}^{\mathrm{D} 56 \mathrm{~A}}$ ), in which the predicted phosphoryl group-accepting Asp56 was replaced by alanine, lost its capacity to get phosphorylated (Figure S2A,B), supporting that D56 is the target residue for phosphorylation. Using electrophoretic mobility shift assays (EMSAs), we found that the addition of acetyl phosphate increased the ability of $6 \mathrm{His}-\mathrm{GltR}$ to bind to the gltB promoter DNA (Figure S2C), while it failed to do this for the $6 \mathrm{His}-\mathrm{GltR}^{\mathrm{D} 56 \mathrm{~A}}$ proteins (Figure S2D). However, the negative control exsA promoter was unbound (Figure S2E). These results indicate that phosphorylation of GltR increases its binding to its target DNA.

Using DNase I foot-printing assays, we found that the 6 His-GltR protected two adjacent sites (I: -44 to -13 , II: -11 to +15 ; relative to the transcriptional initiation site) of the $g l t B$ promoter from DNase I digestion (Figure 2B). These results are consistent with a previous study [26], showing that an DNA sequence (5'-GTGAAAAACCGGA-3') at position -22 to -10 relative to the transcriptional initiation site of $g l t B$ is a GltR-binding site (Figure 2C). However, when compared to those of either the published PAO1 sequence or our laboratory PAO1 reference strain, a single-nucleotide deviation (SNP) and a $1 \mathrm{bp}-$ deletion (5'-GTGAAAAACCGGA-3' vs $5^{\prime}$-GTGACAAACCCGGA-3') were found in the GltR-binding element of the PAO1 strain used in the previous study by Daddaoua et al. [26] (Figure 2C), and this observation supports the notion that P. aeruginosa PAO1 shows an ongoing microevolution [57,58].

Moreover, we found that glucose failed to increase the expression of gltB-D-lux, a gltBlux variant lacking part of GltR-binding site (i.e., 5'-GTGACAAA-3'), in WT P. aeruginosa PAO1 (Figure S2F), suggesting that the binding of GltR to the promoter DNA is essential for the glucose-induced expression of gltBFGK-oprB operon. In addition, disruption of the His280 of GtrS, presumably an essential residue for histidine kinase function [49], abolished the function of GtrS in activating gltB-lux in response to glucose (Figure S3). Collectively, these results clearly suggest that GtrS-GltR TCS positively regulates the gltBFGK-oprB operon via the binding of GltR to the promoter of $g l t B$.

\subsection{2-KG and 6PG Are Not Required for Glucose-Induced Activation of GtrS-GltR}

It has been reported that 2-KG and 6PG bind to the ligand-binding domain of GtrS and increase its autophosphorylation [26]. Intrigued by these findings, we reasoned that 2-KG and 6PG might be factors involved in glucose-induced expression of gltB. To test this hypothesis, we examined the effects of 2-KG and 6PG on the expression of gltB-lux. The addition of either 2-KG $(5 \mathrm{mM})$ or gluconate $(5 \mathrm{mM})$, which can be phosphorylated to 6PG by gluconokinase (GnuK), increased the expression of gltB in WT P. aeruginosa PAO1 by approximately 3.5-fold (Figure $3 \mathrm{~A}$ ), a much lesser extent than that of glucose (about 258-fold, at a final $5 \mathrm{mM}$ concentration) (Figure 3A), implying that 2-KG and 6PG play a far lesser role in determining the activation of GtrS-GltR than glucose.

Because glucose can be oxidized in the periplasm by glucose dehydrogenase (Gcd) and gluconate dehydrogenase (Gad) to gluconate and 2-KG (Figure 1A), we examined the role of Gcd and Gad on glucose-induced activation of GtrS-GltR TCS. We measured the expression level of $g l t B-l u x$, an indicator for the transcriptional regulatory function of GtrS-GltR, in the WT PAO1 strain, the $g c d$ deletion mutant $(\Delta g c d)$, and the gad deletion mutant $(\Delta g a d)$, when bacteria were cultured in M9 minimal medium supplemented with or without glucose $(5 \mathrm{mM})$. The glucose-induced expression level of gltB-lux was decreased by approximately 1.5-fold upon the deletion of either gcd or gad (Figure 3B), suggesting that either gluconate or 2-KG has little effect on the activation of GtrS-GltR in response to glucose. 
A

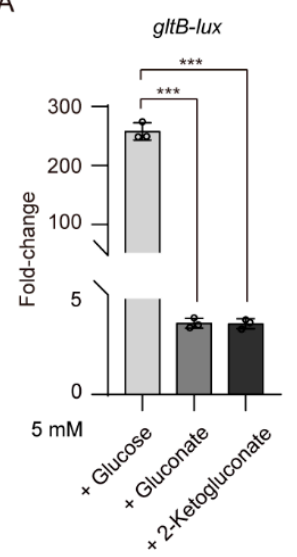

B

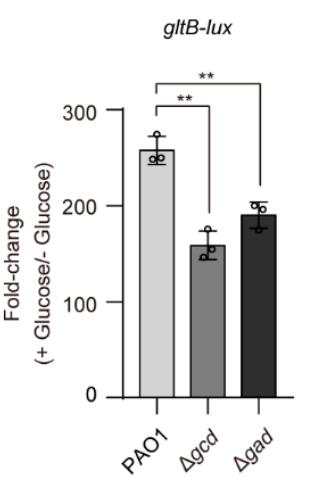

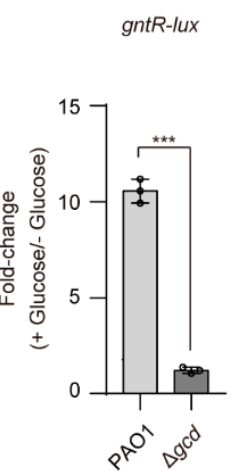<smiles>[134CH3]</smiles>

$\mathrm{E}$

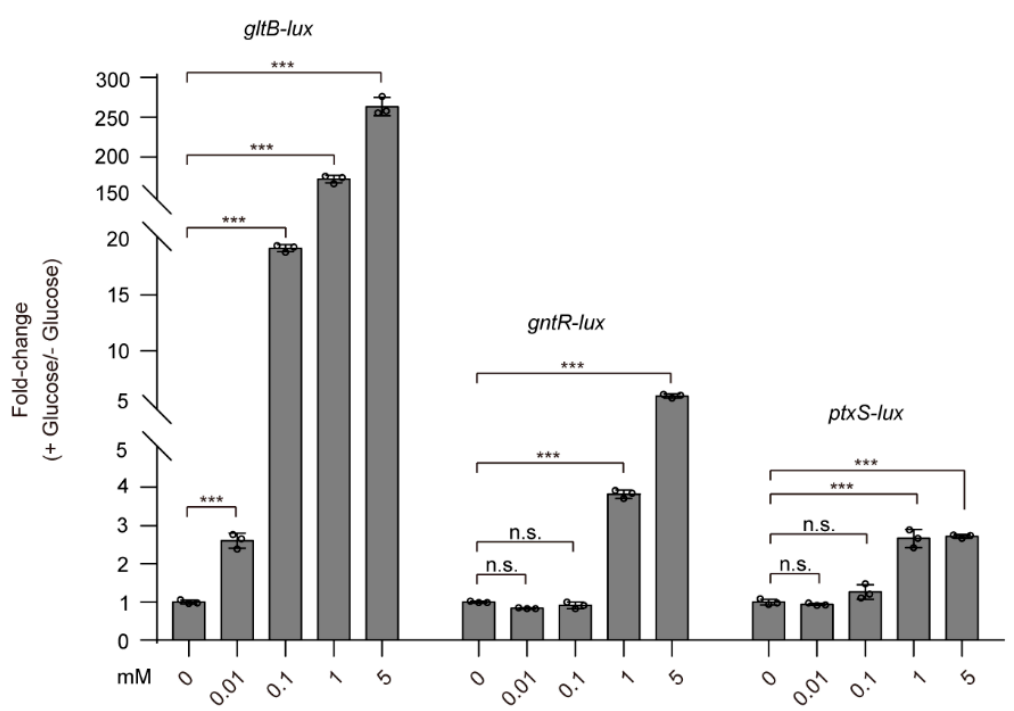

Figure 3. Expression of glucose utilization and metabolism genes. (A) Effect of glucose, gluconate, and 2-ketogluconate on the expression of gltB-lux in WT PAO1 strain grown in tubes containing M9 MM at $37^{\circ} \mathrm{C}$ with shaking (250 rpm) for $8 \mathrm{~h}$. (B) Effect of glucose on the expression of gltB-lux in P. aeruginosa PAO1 and its derivatives grown in tubes containing $\mathrm{M} 9 \mathrm{MM}$ at $37^{\circ} \mathrm{C}$ with shaking (250 rpm) for $8 \mathrm{~h}$. (C,D) Effect of glucose on the expression of gntR-lux (C) and ptxS-lux (D) in P. aeruginosa strains grown in tubes containing M9 MM at $37{ }^{\circ} \mathrm{C}$ with shaking $(250 \mathrm{rpm})$ for $8 \mathrm{~h}$. (E) Effect of different concentrations of glucose on the expression of gltB-lux, gntR-lux, and ptxS-lux in PAO1 cultured in tubes containing M9 MM at $37^{\circ} \mathrm{C}$ with shaking ( $250 \mathrm{rpm}$ ) for $8 \mathrm{~h}$. In (A to E), data from $n=3$ biological replicates reported as mean \pm SD. $\left({ }^{* *} p<0.01,{ }^{* * *} p<0.001\right.$, n.s. indicates no significant difference; Student's two-tailed $t$-test).

Using promoter fusion assays, we showed that $g c d$ deletion, which presumably abolishes the production of gluconate and 2-KG [21,59], severely decreases (more than 70\% reduction) the promoter activities of gnt $R$ and $p t x S$ (Figure 3C,D). These results are well in line with previous studies showing that gluconate and 2-KG, respectively, induces the expression of gntR [25] and $p t x S$ [52], and support the proposed glucose oxidative pathway in the periplasm of P. aeruginosa (Figure 1A). Moreover, we observed that exogenously applied glucose, even at low micromolar concentrations (i.e., $10 \mu \mathrm{M}$ ), was capable of inducing the expression of gltB-lux in P. aeruginosa PAO1 but failed to do for the expression of either gntR-lux or ptxS-lux (Figure 3E). Based on these data, we concluded that unidentified mechanisms for glucose-mediated activation of GtrS-GltR exists in P. aeruginosa. 


\subsection{Genome-Wide Mutagenesis Identifies gltB Is Crucial for GtrS-GltR Activation}

To explore the mechanism by which glucose activates GtrS-GltR, we performed a screen using a library of $P$. aeruginosa PAO1 transposon mutants and a promoter fusion analysis with lacZ reporter (i.e., gltB-lacZ), an indicator of the GtrS-GltR transcriptional activity (Figure 2A). From a transposon mutant library with appropriately 50,000 mutants of WT PAO1, we identified a total of 24 colorless colonies (Table S3, Figure 4A). Of them, $13 \mathrm{had}$ a transposon insertion in either the $g l k-g t r S-g l t R$ operon [60] or its promoter region, and the other 11 had a transposon insertion in the promoter or the coding region of gltB (Table S3, Figure 4A).

A

B
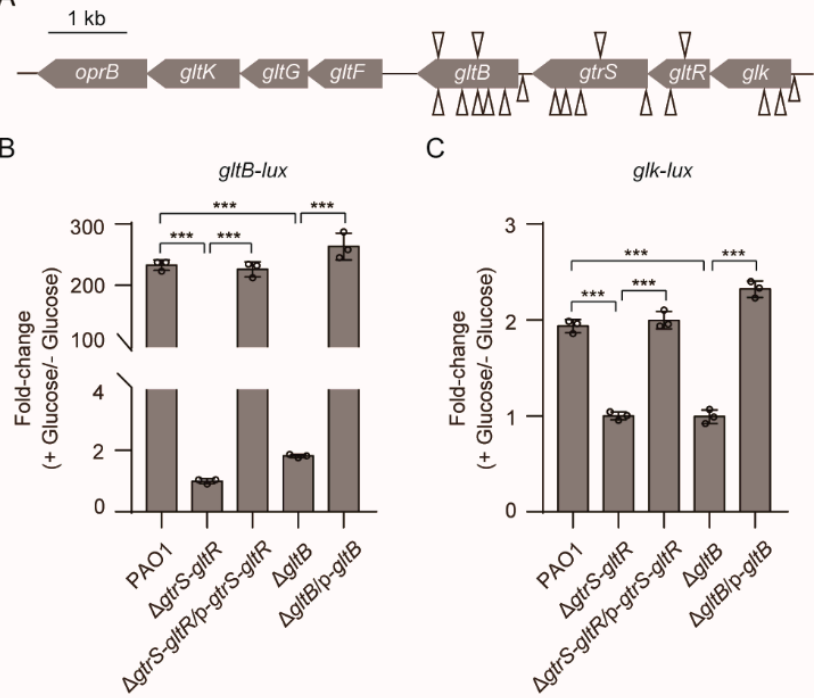

D
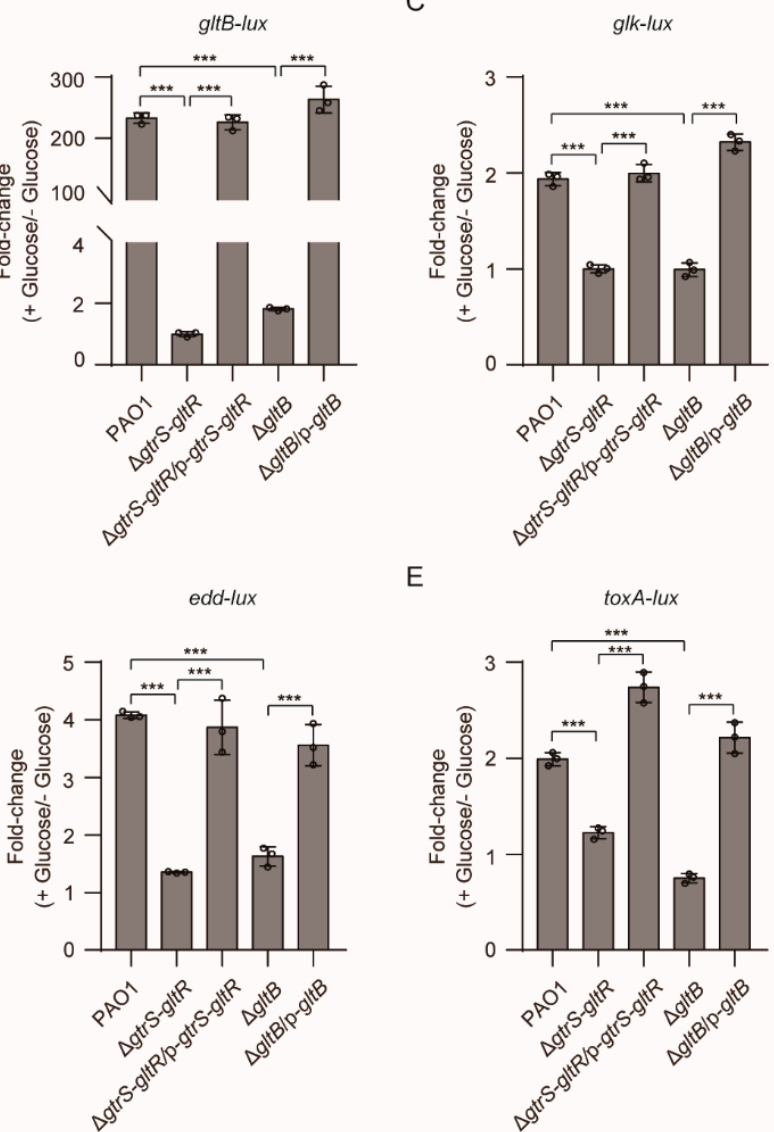

$E$

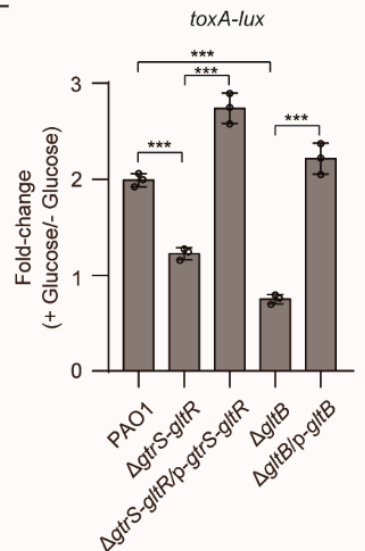

Figure 4. Disruption of $g l t B$ decreases the expression of GltR-regulated genes in response to glucose. (A) Schematic representation of the transposon insertion site. Gene is shown by arrow and the triangle indicated the mariner-based transposon. The direction (relative to the genomic scaffold) of gentamicin resistance cassette in transposon is provided (forward, upper triangles; reverse, lower triangles). (B-E) The effect of either $g t r S$ - $g l t R$ or $g l t B$ deletion on the glucose-induced expression of known GltR-regulated genes. Bacteria were grown in tubes containing M9 MM supplemented with (+) or without (-) $5 \mathrm{mM}$ glucose at $37^{\circ} \mathrm{C}$ with shaking $(250 \mathrm{rpm}$ ) for $8 \mathrm{~h}$, and the fold-change in gene expression (induced by glucose) was determined. Data from $\mathrm{n}=3$ biological replicates reported as mean \pm SD. ( ${ }^{* * *} p<0.001$; Student's two-tailed $t$-test). PAO1, $\Delta g t r S$-gltR, and $\Delta g l t B$ harbor an empty pAK1900 vector as control; p-gtrS-gltR denotes the pAK1900-gtrS-gltR plasmid; p-gltB denotes the pAK1900-gltB plasmid.

To verify the role of gltB in the transcriptional regulatory activity of GtrS-GltR, we deleted $g l t B$ in $P$. aeruginosa PAO1, yielding $\Delta g l t B$ mutant. Similar to the original transposon 
mutant, $\Delta g l t B$ mutant carrying the gltB-lacZ reporter showed colorless colonies when bacteria were grown on M8 minimal agar medium supplemented with $\beta$-galactosidase (X-gal) (Figure S4A,B). Ectopic expression of $g l t B$ in the $\Delta g l t B$ mutant forms intense blue colonies (Figure S4A), indicative of increased expression of gltB-lacZ. These results suggest that GltB plays an important role in the transcriptional regulatory activity of GtrS-GltR against the gltBFGK-oprB operon. Similar result was obtained when the gltB-lux was used as an indicator for the transcriptional regulatory activity of GtrS-GltR (Figure 4B). Moreover, we found that $g l t B$ deletion decreased the glucose-induced promoter activity (Figure 4C-E) of several known GltR-regulated genes including $g l k$, edd, and tox $A$ [26], reinforcing the likelihood that that GltB is crucial for the activation of GtrS-GltR in response to glucose.

\subsection{GltB Binds to a Number of Membrane-Spanning Proteins Including GtrS}

Because GltB is a periplasmic protein $[53,61,62]$, and that GtrS is a membrane-bound histidine kinase [26,63], we thus hypothesized that GltB may interact with GtrS. Using coImmunoprecipitation (Co-IP) experiments with P. aeruginosa PAO1 cells expressing yellow fluorescent protein (YFP)-tagged GtrS (GtrS-YFP), we were able to show that GltB directly interacted with GtrS (Figure 5A). To further confirm this observation, the Co-IP samples were subjected to liquid chromatography-tandem mass spectrometry (LC-MS/MS) analysis. As a result, 250 proteins, including GtrS and a number of membrane-bound proteins, such as PctA, PctB, PilJ, and PA2788 [64,65], were identified as potential GltB interacting proteins (Figure 5B, Table S4).

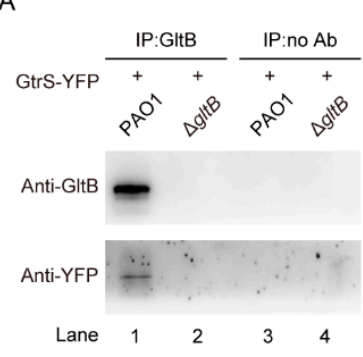

D

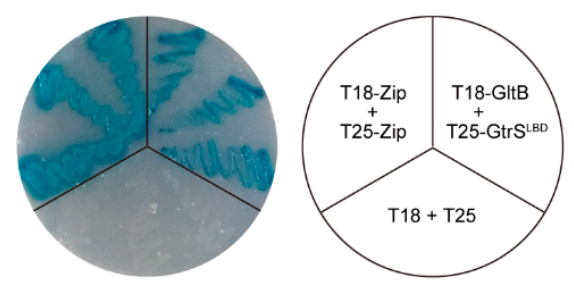

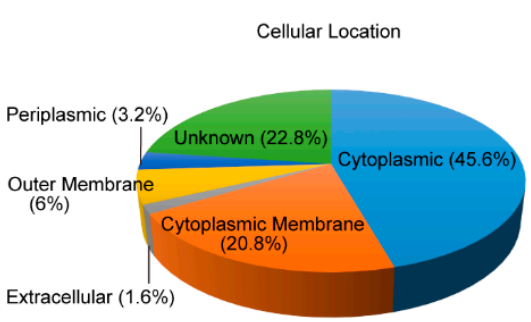

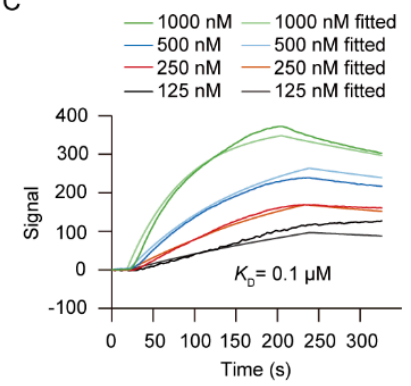

E

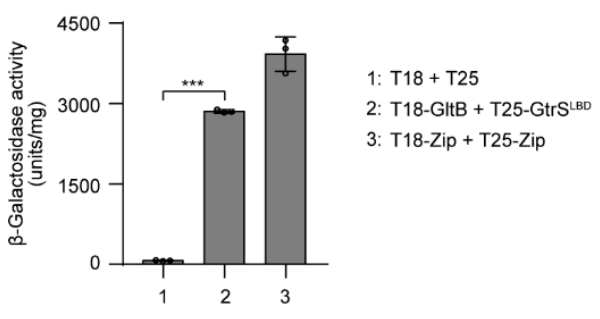

Figure 5. GltB can form a complex with GtrS. (A) Western blot image showing the co-Immunoprecipitation of GltB and GtrS-YFP. Whole cell extracts from WT PAO1 and $\Delta g l t B$ mutant strains expressing gtrS-YFP were immunoprecipitated with (lanes 1, 2) or without (lanes 3, 4) anti-GltB antibody. (B) Categories of the putative GltB-binding proteins identified by coImmunoprecipitation coupled with mass spectrometric (CoIP-MS). The identified proteins were classified into extracellular, outer membrane, periplasmic, cytoplasmic membrane, cytoplasmic, and unknown according to their potential cellular location (http:/ / www.pseudomonas.com/ accessed on 1 May 2020). Percentage of proteins was indicated in the graph. (C) Surface plasmon resonance (SPR) analysis showing the interaction of $6 \mathrm{His}-\mathrm{GltB}$ with $6 \mathrm{His}-\mathrm{GtrS}{ }^{\mathrm{LBD}}$. Analysis performed in TraceDrawer using a 1:1 binding interaction model. $K_{\mathrm{D}}$, equilibrium dissociation constant. (D and E) Bacterial two-hybrid (BACTH) assays assessing the interaction of GltB and GtrS ${ }^{\mathrm{LBD}}$. In (D), E. coli BTH101 recombinants bearing indicated combinations of plasmids were plated on selective media with maltose as the unique carbon source, and incubated at $30{ }^{\circ} \mathrm{C}$ for 6 days; in (E), the expression of $\beta$-galactosidase activity was examined in E. coli BTH101 recombinants bearing indicated combinations of plasmids cultured in LB broth containing $0.5 \mathrm{mM}$ isopropyl-1-thio- $\beta$-d-galactopyranoside (IPTG) for $12 \mathrm{~h}$, and data represented mean $\pm \mathrm{SD}$ from $\mathrm{n}=3$ biological replicates ( ${ }^{* * *} p<0.001$; Student's two-tailed $t$-test). T18C/T25 (negative control plasmid), T18C-zip/T25-zip (positive control plasmid). 
Using surface plasmon resonance (SPR) analysis, we determined that 6 His-GltB bound to 6 His-GtrS ${ }^{\mathrm{LBD}}$ (N-terminally 6 His-tagged ligand-binding domain of GtrS, residues $29-199)$ with a dissociation constant $\left(K_{\mathrm{D}}\right)$ of $0.1 \mu \mathrm{M}$ (Figure $5 \mathrm{C}$ ), which is much lower than the dissociation constant of either 2-KG (i.e., $5 \mu \mathrm{M}$ ) or 6-phosphogluconate (i.e., $98 \mu \mathrm{M}$ ) binding to the recombinant GtrS ligand-binding domain [26]. We also found that 6 HisGltB bound to 6 His-PctA ${ }^{\mathrm{LBD}}$ (N-terminally 6His-tagged ligand-binding domain of PctA, residues $30-278$ ) and 6 His-PA2788 ${ }^{\mathrm{LBD}}$ (N-terminally 6 His-tagged ligand-binding domain of PA2788, residues 44-179) with $K_{\mathrm{D}}$ values of $0.8 \mu \mathrm{M}$ and $0.4 \mu \mathrm{M}$, respectively (Figure S5A,B), indicating that GltB may have broad function in the responses of $P$. aeruginosa to glucose. To further examine the binding of GltB to GtrS, we employed a bacterial two-hybrid system and demonstrated GltB was capable of interacting with GtrS in Escherichia coli (Figure 5D,E). Based on these data, we concluded that GltB interacts with GtrS in P. aeruginosa.

\subsection{GltB Requires Its Glucose-Binding Pocket to Activates GtrS-GltR}

It has been established that GltB is a glucose-specific binding protein (Figure 1A). In line with this, the addition of glucose increased the melting temperature (Tm) of GltB in a concentration-dependent manner (Figure 6A). This result suggests that GltB binds to glucose because when a protein binds to a ligand, its melting temperature $(\mathrm{Tm}) \mathrm{might}$ shift $[66,67]$. Using isothermal titration calorimetry (ITC) analysis, we found that 6His-GltB bound to glucose with the equilibrium dissociation constant $\left(K_{\mathrm{D}}\right)$ of $1.37 \mu \mathrm{M}$ (Figure $6 \mathrm{~B}$ ), a value close to that measured in either surface plasmon resonance (SPR) [55] or the equilibrium dialysis experiment [53].

Twelve residues (i.e., W35, W36, E41, G68, Q90, K92, W250, W270, N301, D303, K339, and H379) present in the substrate binding pocket of Pseudomonas putida CSV86 GltB are directly involved in glucose binding $[54,55]$. To examine the role of the substrate binding pocket of $P$. aeruginosa GltB in the activation of GtrS-GltR, five residues W33, W34, K90, W268, and D301, which correspond to the W35, W36, K92, W270, and D303 of the P. putida CSV86 GltB [54,55], were, respectively, mutated to alanine using sitedirected mutagenesis. As shown in Figure 6C, each alanine substitution had no obvious effect on the expression/stability of the GltB protein. However, K90A and W268A amino acid substitutions, respectively, decreased the glucose-induced expression of gltB-lux by approximately $50 \%$ in a $\Delta g l t B$ strain (Figure $6 \mathrm{D}, \mathrm{E}$ ), and notably either W33A, W34A, or D301A amino acid substitution totally abolished the glucose-induced expression of gltBlux (Figure 6D,E). Additionally, we observed that glucose failed to increase the Tm of the GltB ${ }^{\mathrm{D} 301 \mathrm{~A}}$ (Figure $6 \mathrm{~F}$ ), which suggests that this conserved residue is required for $P$. aeruginosa $\mathrm{GltB}$ to bind to glucose. These result suggest that the glucose-binding is required for GltB to exert its regulatory function against the GtrS-GltR TCS. 
A

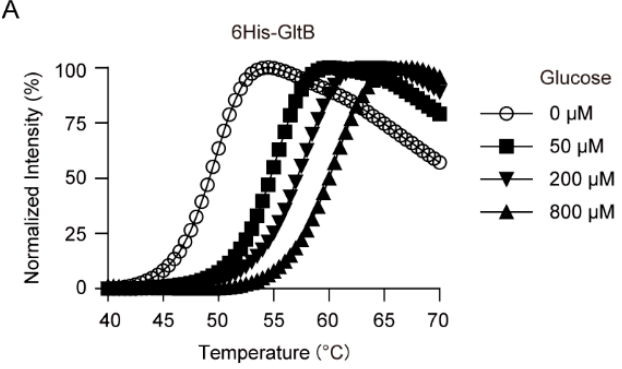

C

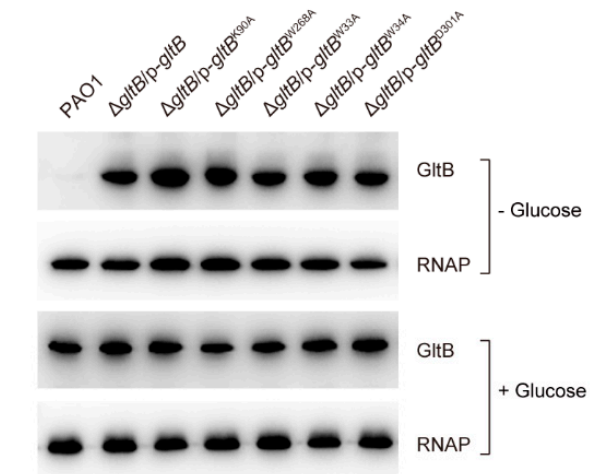

E

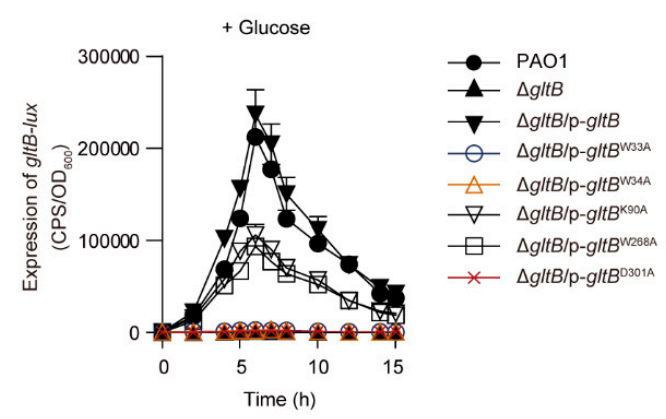

B

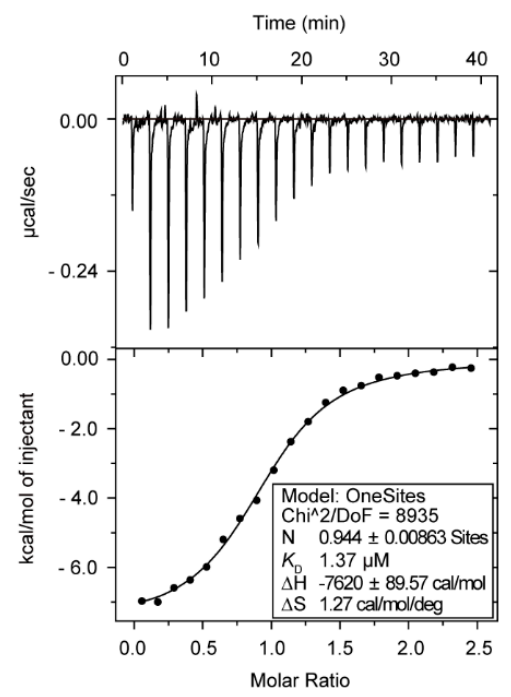

D
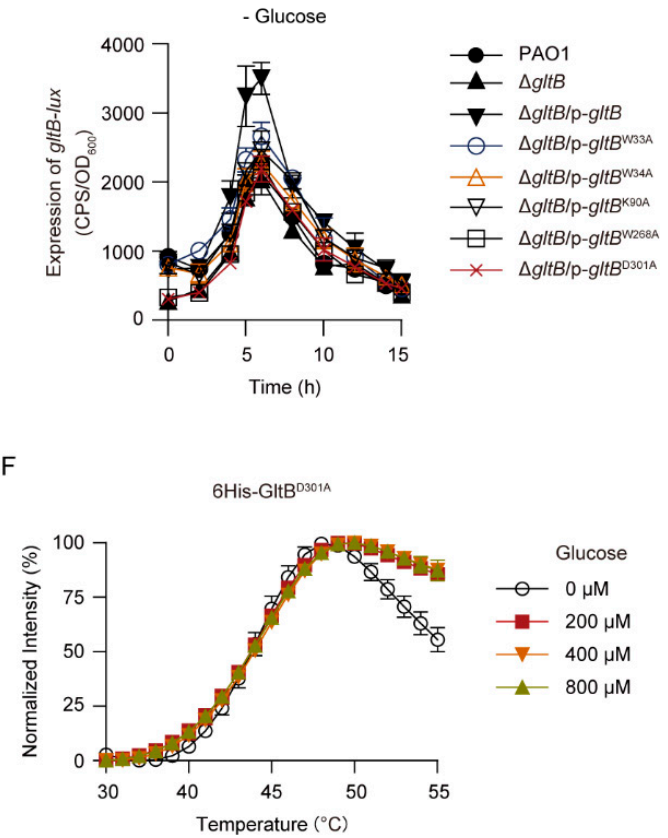

Figure 6. Role of glucose-binding residues on the regulatory function of GltB. (A) Thermal melt curves of $5 \mu \mathrm{M} 6 \mathrm{His}-\mathrm{GltB}$ in the presence of indicated glucose concentrations. (B) Isothermal titration calorimetry of $6 \mathrm{His}-\mathrm{GltB}(17 \mu \mathrm{M})$ with glucose $(200 \mu \mathrm{M})$. Upper panel, raw data output; lower panel, plot of integrated heats versus the glucose/6His-GltB ratio. Data was fitted with a one-site model. The fitted results are displayed: $\mathrm{N}$ refers to the stoichiometry of GltB-glucose complex, $K_{\mathrm{D}}$ refers to the equilibrium dissociation constant, $\Delta H$ (reaction enthalpy) and $\Delta S$ (entropy) are the thermodynamic parameters. (C) Western blot images showing the production of GltB and its variants. Protein samples were derived from bacteria grown in tubes containing M8 MM in the absence (-) or presence (+) of $10 \mathrm{mM}$ glucose at $37^{\circ} \mathrm{C}$ for $6 \mathrm{~h}$ with shaking (250 rpm). RNAP subunit is probed as a loading control. Experiments were repeated at least three times with similar results and the figures show a set of representative data. (D,E) Expression of gltB-lux in P. aeruginosa strains cultured in 96-well plates containing M8 MM supplemented with (+) or without (-) $10 \mathrm{mM}$ glucose. Data from $\mathrm{n}=3$ biological replicates reported as mean \pm SD. In (D and E), PAO1 and $\Delta g l t B$ harbor an empty pAK1900 vector as control; $\mathrm{p}$ - $g l t B$ denotes the pAK1900- $g l t B$ plasmid; p- $g l t B^{\mathrm{W} 33 \mathrm{~A}}, \mathrm{p}-g l t B^{\mathrm{W} 34 \mathrm{~A}}, \mathrm{p}-g l t B^{\mathrm{K} 90 \mathrm{~A}}, \mathrm{p}-g l t B^{\mathrm{W} 268 \mathrm{~A}}$, and $\mathrm{p}-g l t B^{\mathrm{D} 301 \mathrm{~A}}$ denote the pAK1900- $g l t B^{\mathrm{W} 33 \mathrm{~A}}$ plasmid, the pAK1900- $g l t B^{\mathrm{W} 34 \mathrm{~A}}$ plasmid, the pAK1900- $g l t B^{\mathrm{K} 90 \mathrm{~A}}$ plasmid, the pAK1900- $g l t B^{\mathrm{W} 268 \mathrm{~A}}$ plasmid, and the pAK1900- $g l t B^{\mathrm{D} 301 \mathrm{~A}}$ plasmid, respectively (Table S1). (F) Thermal melt curves of $5 \mu \mathrm{M} 6 \mathrm{His}-\mathrm{Glt}^{\mathrm{D} 301 \mathrm{~A}}$ in the presence of indicated glucose concentrations. In (A) and (F), fluorescence signals of all samples have been normalized to relative values of $0 \%$ (the lowest fluorescence signal) and $100 \%$ (the highest fluorescence signal), respectively. 


\subsection{Genome-Wide Identification of GltR Targets}

As aforementioned, GltB binds to GtrS and increases the promoter activity of known GltR-regulated genes (i.e., $g l t B, g l k$, edd, and toxA) (Figure 4B-E, Figure 5). To further verify the role of GltB in the regulatory function of GtrS-GltR TCS, we sought to explore the additional GltR-regulated genes. To this end, we performed chromatin immunoprecipitation followed by high-throughput sequencing (CHIP-seq) assays with a PAO1::gltR-flag strain expressing a functional C-terminally tagged GltR protein (GltR-flag). Using the MACS software [43], we identified 55 significantly enriched loci (fold change $\geq 3$ and q-value $<$ 0.05) (Table S5, Figure 7A).
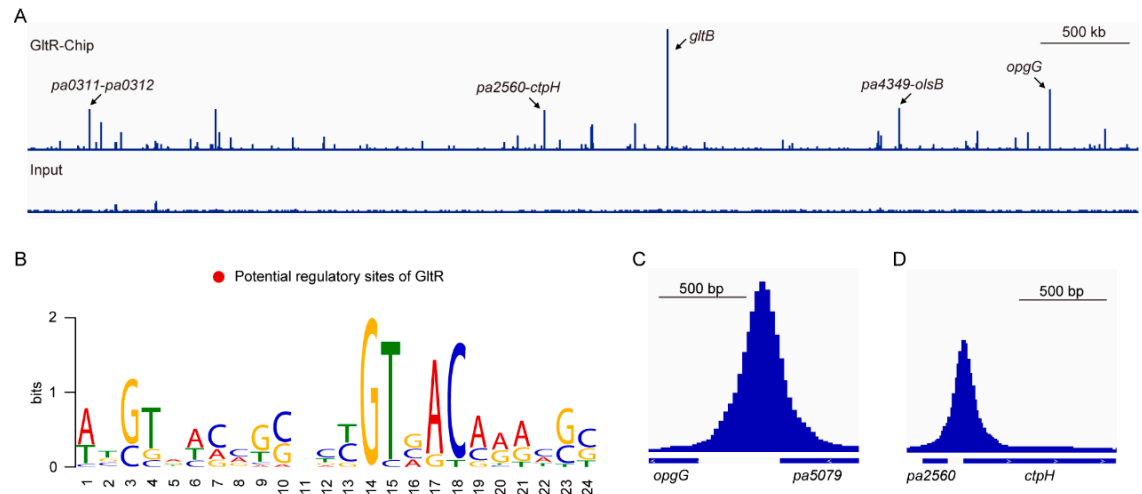
opg G promoter DN

G
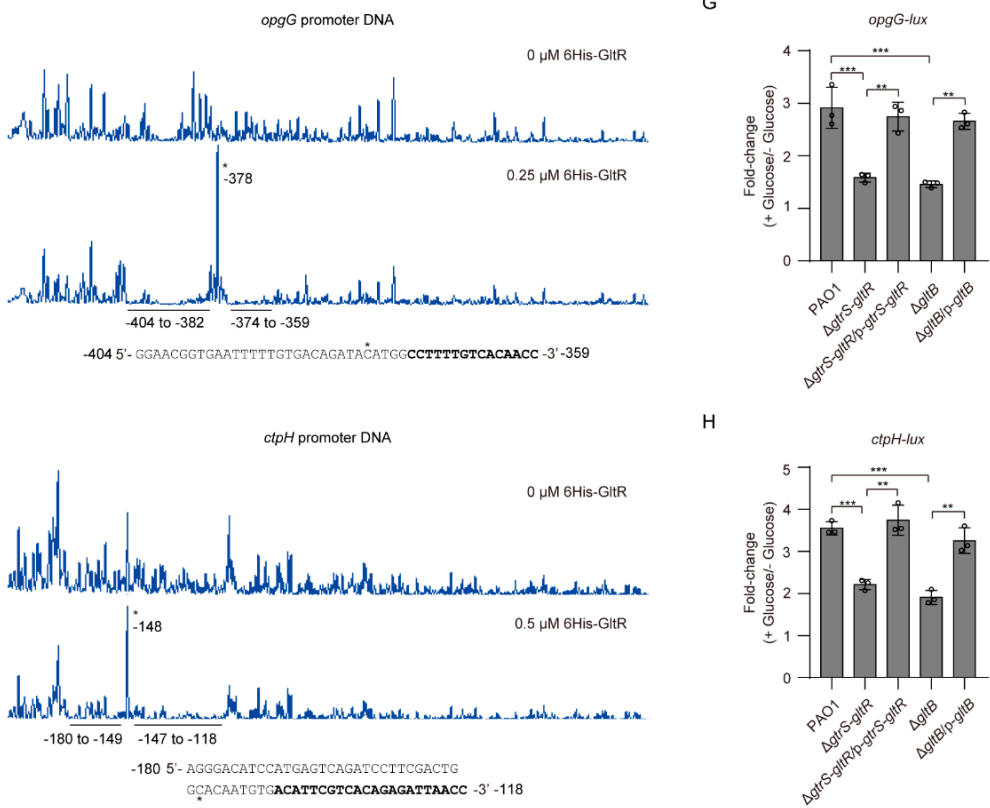

Figure 7. Genome-wide identification of GltR targets. (A) Images showing GltR-binding sites identified by CHIP-seq. The top five of CHIP-seq peaks were labeled. (B) The most significant motif (E-value $=1.3 \times 10^{-6}$ ) identified by MEME tool was observed in all DNA sequences of the 16 tested peaks ( $\geq 10$-fold enrichment, in average). The height of each letter represents the relative frequency of each base at different position in the consensus sequence. (C,D) Pattern of CHIP-seq peaks identified in intergenic regions of opgG-pa5079 (C) and pa2560-ctpH (D). (E and F) Electropherograms show the protection patterns of the $\operatorname{pog}_{\mathrm{g}}(\mathbf{E})$ and $\operatorname{ctpH}(\mathbf{F})$ promoter DNA after digestion with DNase I following incubation in the absence or presence of 6 His-GltR. The protected region (relative to the start codon) is underlined, and the asterisk indicates the DNase I hypersensitivity site. The sequences including GltR-protected regions are shown, and the conserved sequence identified by MEME of GltR-binding sites are shown in bold. ( $\mathrm{G}$ and $\mathrm{H}$ ) Effect of either $g t r S-g l t R$ or $g l t B$ deletion on the expression of opgG-lux $(\mathbf{G})$ and $\operatorname{ctpH}-\operatorname{lux}(\mathbf{H})$. Bacteria were grown in tubes containing M9 MM supplemented with (+) or without (-) $5 \mathrm{mM}$ glucose at $37^{\circ} \mathrm{C}$ with shaking $(250 \mathrm{rpm}$ ) for $8 \mathrm{~h}$. Data from $\mathrm{n}=3$ biological replicates reported as mean \pm SD. $\left({ }^{* *} p<0.01,{ }^{* * *} p<0.001\right.$; Student's two-tailed $t$-test). PAO1, $\Delta g t r S$ - $g l t R$, and $\Delta g l t B$ harbor an empty pAK1900 vector as control; p-gtrS-gltR denotes the pAK1900-gtrS-gltR plasmid; p-gltB denotes the pAK1900-gltB plasmid. 
The most enriched locus by CHIP-seq experiments was the promoter region of $g l t B$ ( 75-fold enrichment) (Table S5, Figure 7A), suggesting that GltR strongly binds to the promoter of gltB under the test condition. Using MEME tool [44], we found that the most significant motif $\left(E-v a l u e=1.3 \times 10^{-6}\right)$ containing a consensus $5^{\prime}$-GTNACAAA-3' sequence (in positions 14-21, where $\mathrm{N}$ is any nucleotide) (Figure 7B), which matches the GltR-binding site (i.e., GTGACAAA) revealed by footprint assays on the gltB promoter (Figure 2B), was enriched in the $101 \mathrm{bp}$ region centered at the summits for all tested 16 peaks ( $\geq 10$-fold enrichment). These results support the effectiveness of the CHIP-seq procedure and indicate that the determination of GltR-binding consensus sequence was carried out successfully.

Among the 55 potential GltR-binding sites, 61.8\% (34 peaks) are in the potential promoters (within $500 \mathrm{bp}$ of the translational start site) of P. aeruginosa genes (Table S5). Because some GltR-binding sites are flanked by divergently transcribed genes (or operons), GltR binding within the 34 regions could potentially control the expression of 112 genes in 48 transcription units (TUs) (Table S5). Functional analyses showed that these potential GltR-targeted genes are associated with various biological functions including glucose transport (e.g., gltB), synthesis of glucans (e.g., opgGH operon), phosphate taxis (e.g., ctpH), and copper tolerance (e.g., copR and ptrA) (Table S5).

\subsection{GltB Positively Regulates opgGH and ctpH, Two New GltR Targets}

As described above, our CHIP-seq experiments showed that opgGH operon and ctpH are potential GltR targets (Figure 7A,C,D). In P. aeruginosa, the opgGH operon is required for the biosynthesis of osmoregulated periplasmic glucans (OPGs) involved in osmoprotection, biofilm formation, virulence, and resistance to antibiotics [68], while the $\operatorname{ct} p H$ encodes a chemotactic transducer for inorganic phosphate [69]. Using EMSA assays, we verified that GltR bound to the promoters of opgGH operon and $c t p H$ (Figure S6A,B). In the presence of acetyl phosphate, the 6His-GltR bound to those promoter DNAs with stronger affinity, whereas acetyl phosphate has no obvious effect on the binding of $6 \mathrm{His}-\mathrm{GltR}{ }^{\mathrm{D} 56 \mathrm{~A}}$ to the promoter DNAs (Figure S6C,D). As the negative control, the exsA promoter was unbound (Figure S6E). Using DNase I foot-printing experiments, we found that 6 His-GltR protected two adjacent sites $(-404$ to $-382 ;-374$ to -359 ; relative to the start codon) of the opgG promoter from DNase I digestion (Figure 7E). Similarly, 6His-GltR also protected two adjacent sites ( -180 to $-149 ;-147$ to -118 ; relative to the start codon) of the $c t p H$ promoter from DNase I digestion (Figure 7F).

To examine whether GtrS-GltR TCS has a role in modulating the expression of opgGH operon and $c t p H$. We measured the promoter activity of $o p g G$ and $c t p H$ in WT PAO1 strain, $g t r S-g l t R$ deletion mutant $(\Delta g t r S-g l t R)$, and its complemented strain $\Delta g t r S-g l t R / p$ - $g t r S-g l t R$, respectively. Deletion of $g t r S$ - $g l t R$ resulted in an approximately 2 -fold decrease in glucoseinduced expression of opgG-lux in the P. aeruginosa PAO1, and the reduced expression of opgG-lux was fully restored upon introduction of $g t r S$ - $g l t R$ with a plasmid (i.e., p-gtrS-gltR) (Figure 7G). Similar results were observed when the ctpH-lux was examined (Figure $7 \mathrm{H}$ ). These results, together with the biochemical evidence of direct binding of GltR with the promoter DNA of opgG and $c t p H$ (Figure S6A,B), suggest that opgGH operon and $c t p H$ are GltR targets.

We next investigated the role of GltB in the expression of opgGH operon and $c t p H$. We performed the promoter analysis again and found that the glucose-induced expression level of both opgG-lux and ctpH-lux in $\Delta g l t B$ was similar to that of the $\Delta g t r S-g l t R$ (Figure $7 \mathrm{G}, \mathrm{H}$ ). Introduction of plasmid-borne $g l t B$ into the $\Delta g l t B$ restored the expression of either opgG-lux or ctpH-lux to wild-type PAO1 levels (Figure 7G,H), demonstrating that like GtrS-GltR TCS, GltB activates the expression of $o p g G H$ operon and $c t p H$ as well. Collectively, these results reinforce the likelihood that GltB is required for the glucose-induced activation of GtrS-GltR (Figure 4). 


\subsection{GltB Is Important for the Pathogenicity of P. aeruginosa}

GtrS is important for P. aeruginosa infection [60,63]. In line with this, we found that $\Delta g t r S$ mutant exhibited reduced virulence against infected flies compared with the WT P. aeruginosa PAO1 in a Drosophila melanogaster nicking infection model (Figure 8A). We also found that the virulence phenotype of $\Delta g l t B$ resembled that of the $\Delta g t r S$, and the virulence defect phenotype of $\Delta g l t B$ was complemented in trans with plasmid-borne copies of the gltB (Figure 8A).

A

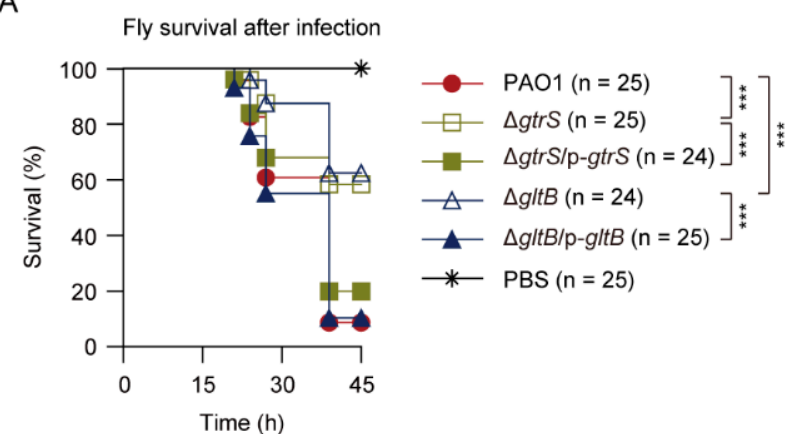

B

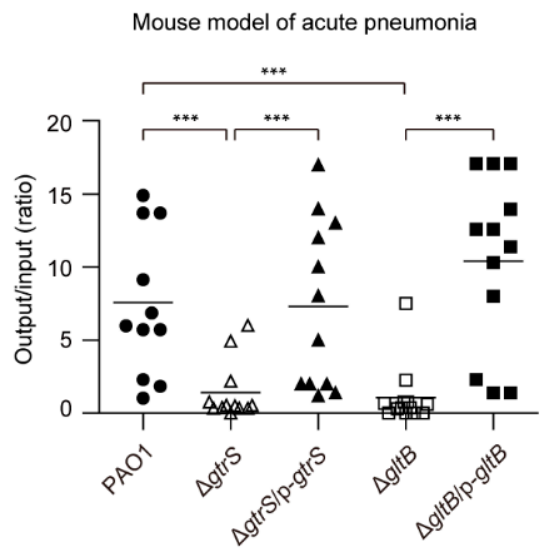

Figure 8. Role of GltB in P. aeruginosa virulence. (A) Survival rates of fly upon infection by indicated $P$. aeruginosa strains. $\mathrm{n}$ indicates the number of flies used. Asterisks denote statistical significance determined by log-rank Test: ${ }^{* * *} p<0.001$. PBS indicates flies was pricked with a sterilized tungsten needle dipped in phosphate buffer saline (PBS) buffer. (B) Recovery of P. aeruginosa in a mouse model of acute pneumonia. Results are expressed as the ratio of CFU (colony-forming unit) recovered per lung (output) to CFU present in the initial inoculum (input). Data represent results from $\mathrm{n}=10-12$ mice per strain; the line shows the geometric mean for each group. The Mann-Whitney test was used to calculate $\mathrm{p}$-values (two-tailed): ${ }^{* * *} p<0.001$. In all panels, PAO1, $\Delta g t r S$, and $\Delta g l t B$ harbor an empty pAK1900 vector as control; p-gtrS denotes the pAK1900-gtrS plasmid; p-gltB denotes the pAK1900-gltB plasmid.

To further examine the role of GltB and GtrS in the pathogenicity of P. aeruginosa, the WT PAO1, $\Delta g t r S, \Delta g l t B$, and complemented strains $\Delta g t r S / \mathrm{p}$ - $g t r S$ and $\Delta g l t B / \mathrm{p}$ - $g l t B$ were inoculated in a mouse model of acute pneumonia. Figure $8 \mathrm{~B}$ shows the colony-forming unit (CFU) of bacteria recovered from the lungs compared to the initial inoculum at $18 \mathrm{~h}$ post infection, with a geometric mean indicated for each group. The WT PAO1 was able to colonize the lungs of infected mice, and the number increased by approximately $570 \%$ over the course of the $18 \mathrm{~h}$ infection (Figure $8 \mathrm{~B}$ ). In contrast, the $\Delta g t r S$ and $\Delta g l t B$ bacteria were, respectively, recovered in numbers approximately at $52 \%$ and $38 \%$ of initial inoculum dose from lungs (Figure 8B). In complemented strains, the colonization was completely restored to WT levels (Figure 8B). Taken together, these results suggest that GltB is important for the activation of GtrS-GltR TCS during infections. 


\section{Discussion}

In this study, we show that periplasmic glucose-binding protein GltB is required for the activation of GtrS-GltR TCS in P. aeruginosa. We provide the first proteome-wide analysis of GltB-binding proteins (Figure 5B, Table S4,) and the first genome-wide analysis of the GltR targets (Figure 7A, Table S5), laying the ground for a better understanding of signaling pathways engaged by GltB and GtrS-GltR.

GltB is one of periplasmic substrate-binding protein (PBPs) [20,53]. In gram-negative bacteria, PBPs constitute a large family of receptors that recognize and deliver small molecules or ions into the cytoplasm via the cognate inner membrane ATP binding cassette $(\mathrm{ABC})$ transport systems [70]. Although the main function of PBPs is the involvement in transport processes, PBPs were found to possess a number of additional functions and there is increasing evidence for PBP mediated activation of chemoreceptors and sensor kinases [46,71-74]. In this work we showed that GltB binds to and induces the transcriptional regulatory activity of GtrS-GltR TCS (Figure 4B-E, Figure 5). Interestingly, GltB was also capable of binding to a number of proteins including chemoreceptor PctA [75] and predicted membrane chemotaxis transducer PA2788 [65] (Figure S5A,B, Table S4,). Therefore, GltB may have a much more profound effect on the cellular function of $P$. aeruginosa than we previously thought, and further studies are required to address this important issue.

We showed that GltR is a positive transcriptional regulator for gltBFGK (gts $A B C D$ )oprB operon that encodes the glucose transport system [28] (Figure 2A). This result is consistent with some previous studies, where it has been found that GltR acts as an activator of the glucose transport system in P. aeruginosa [20,27] and in Pseudomonas putida [29]. However, there has also been contradicting report on the role or mechanism of this regulation. Daddaoua and colleagues described GltR as a repressor [26]. These differences may be explained by strain-to-strain differences because P. aeruginosa PAO1 shows an ongoing microevolution of genotype and phenotype [57,58]. Indeed, analysis of the promoter sequence of $g l t B$ pointed to the existence of single-nucleotide polymorphism (SNP) and small deletion in the PAO1 strain used in the studies by Daddaoua et al. [26] compared to the published PAO1 sequence (Figure 2C).

Many studies have suggested that the effect of glucose on $P$. aeruginosa virulence is of medical relevance [11,60,76-82]. Interestingly, glucose appears to contribute to the virulence evolution of $P$. aeruginosa DK2, a transmissible clone isolated from chronically infected Danish CF patients over a period of 38 years [83,84], by activating BfmRS TCS via the GltB and GtrS-GltR [49]. In addition to acting as a nutrient for P. aeruginosa growth, glucose may also serve as a signal molecule that induces virulence functions because micromolar glucose could increase the transcriptional regulatory activity of GtrS-GltR that play an important role in P. aeruginosa virulence [63] (Figure 3E, Figure 4E, and Figure 8).

In conclusion, the results from this study suggested that GltB interacts with GtrS and initiates the GtrS-GltR signaling cascade that allows P. aeruginosa to respond to the presence of glucose. A deeper understanding of mechanism of action of GltB/GtrS-GltR regulatory axis may lead to more effective methods of treatment of $P$. aeruginosa infections.

Supplementary Materials: The following are available online at https:/ /www.mdpi.com/2076-2 607/9/2/447/s1, Figure S1: The growth curve of P. aeruginosa strains. Figure S2: Phosphorylation assays, electrophoretic mobility shift assays, and promoter activity assays. Figure S3: Effect of H280A amino acid substituent in GtrS on the transcriptional regulatory activity of GtrS-GltR. Figure S4: Effect of gene disruption in PAO1 on the expression of gltB-lacZ. Figure S5: GltB interacts with chemotaxis proteins. Figure S6: Electrophoretic mobility shift assays. Table S1: Plasmids and bacterial strains and used in this study. Table S2: Primers used in this study. Table S3: Transposon insertion sites. Table S4: Protein list obtained from LC-MS/MS(PXD020213). Table S5: Annotated CHIP-seq peaks.

Author Contributions: C.X. and L.L. conceived and initiated the study. C.X. did most experiments. C.X., Q.C. and L.L. analysed the data. C.X. and L.L. wrote the manuscript. All authors discussed 
the results and commented on the manuscript. All authors have read and agreed to the published version of the manuscript.

Funding: This work was supported by grants from National Natural Science Foundation (NSFC) (grant nos. 31870127 and 81861138047) and the Ministry of Science and Technology (MOST) of China (grant no. 2016YFA0501503 and 2019ZX09721001-004-003). This study was also funded by the Science and Technology Commission of Shanghai Municipality (grant no. 19JC1416400) and State Key Laboratory of Drug Research (SIMM2003ZZ-03).

Institutional Review Board Statement: Animal experiments were performed in strict accordance with the regulations for the Administration of Affairs Concerning Experimental Animals approved by the State Council of People's Republic of China (11-14-1988). The animal study protocols were reviewed and approved by the Institutional Animal Care and Use Committee (IACUC) of the Shanghai Public Health Clinical Center (permit 2013P201) and were performed in ac-cordance with the relevant guidelines and regulations. The laboratory animal usage li-cense number is SYXK-HU2010-0098, certified by Shanghai Committee of Science and Technology.

Informed Consent Statement: Not applicable.

Data Availability Statement: Data available in a publicly accessible repository.

Acknowledgments: We appreciate LC-MS/MS assays and the corresponding initial data analysis from Institutional Center for Shared Technologies and Facilities of SIMM, CAS.

Conflicts of Interest: The authors declare no conflict of interest.

\section{References}

1. Nakrani, M.N.; Wineland, R.H.; Anjum, F. Physiology, Glucose Metabolism; StatPearls Publishing LLC.: Treasure Island, FL, USA, 2020

2. Philips, B.J.; Redman, J.; Brennan, A.; Wood, D.; Holliman, R.; Baines, D.; Baker, E.H. Glucose in bronchial aspirates increases the risk of respiratory MRSA in intubated patients. Thorax 2005, 60, 761-764. [CrossRef]

3. Brennan, A.L.; Gyi, K.M.; Wood, D.M.; Johnson, J.; Holliman, R.; Baines, D.L.; Philips, B.J.; Geddes, D.M.; Hodson, M.E.; Baker, E.H. Airway glucose concentrations and effect on growth of respiratory pathogens in cystic fibrosis. J. Cyst. Fibros. 2007, 6, 101-109. [CrossRef]

4. Valdes, K.M.; Sundar, G.S.; Belew, A.T.; Islam, E.; El-Sayed, N.M.; Le Breton, Y.; McIver, K.S. Glucose levels alter the Mga virulence regulon in the Group A Streptococcus. Sci. Rep. 2018, 8, 4971. [CrossRef] [PubMed]

5. Feng, X.; Tran, K.D.; Sanchez, M.A.; Al Mezewghi, H.; Landfear, S.M. Glucose transporters and virulence in Leishmania mexicana. mSphere 2018, 3, e00349-18. [CrossRef] [PubMed]

6. Meireles, P.; Sales-Dias, J.; Andrade, C.M.; Mello-Vieira, J.; Mancio-Silva, L.; Simas, J.P.; Staines, H.M.; Prudêncio, M. GLUT1mediated glucose uptake plays a crucial role during Plasmodium hepatic infection. Cell Microbiol. 2017, 19, e12646. [CrossRef]

7. Thurlow, L.R.; Stephens, A.C.; Hurley, K.E.; Richardson, A.R. Lack of nutritional immunity in diabetic skin infections promotes Staphylococcus aureus virulence. Sci. Adv. 2020, 6, eabc5569. [CrossRef]

8. Jiang, L.; Wang, P.; Song, X.; Zhang, H.; Ma, S.; Wang, J.; Li, W.; Lv, R.; Liu, X.; Ma, S.; et al. Salmonella Typhimurium reprograms macrophage metabolism via T3SS effector SopE2 to promote intracellular replication and virulence. Nat. Commun. 2021, 12, 1-18. [CrossRef]

9. Tucey, T.M.; Verma, J.; Olivier, F.A.B.; Lo, T.L.; Robertson, A.A.B.; Naderer, T.; Traven, A. Metabolic competition between host and pathogen dictates inflammasome responses to fungal infection. PLoS Pathog. 2020, 16, e1008695. [CrossRef]

10. Chen, X.; Zhang, Z.; Chen, Z.; Li, Y.; Su, S.; Sun, S. Potential antifungal targets based on glucose metabolism pathways of candida albicans. Front. Microbiol. 2020, 11, 296. [CrossRef] [PubMed]

11. Raneri, M.; Pinatel, E.; Peano, C.; Rampioni, G.; Leoni, L.; Bianconi, I.; Jousson, O.; Dalmasio, C.; Ferrante, P.; Briani, F. Pseudomonas aeruginosa mutants defective in glucose uptake have pleiotropic phenotype and altered virulence in non-mammal infection models. Sci. Rep. 2018, 8, 16912. [CrossRef]

12. Vitko, N.P.; Grosser, M.R.; Khatri, D.; Lance, T.R.; Richardson, A.R. Expanded glucose import capability affords Staphylococcus aureus optimized glycolytic flux during infection. mBio 2016, 7, e00296-16. [CrossRef]

13. Stover, C.K.; Pham, X.Q.; Erwin, A.L.; Mizoguchi, S.D.; Warrener, P.; Hickey, M.J.; Brinkman, F.S.L.; Hufnagle, W.O.; Kowalik, D.J.; Lagrou, M.; et al. Complete genome sequence of Pseudomonas aeruginosa PAO1, an opportunistic pathogen. Nature 2000, 406, 959-964. [CrossRef]

14. National Nosocomial Infections Surveillance. National Nosocomial Infections Surveillance (NNIS) System Report, data summary from January 1992 through June 2004, issued October 2004. Am. J. Infect. Control 2004, 32, 470-485. [CrossRef]

15. Willyard, C. The drug-resistant bacteria that pose the greatest health threats. Nature 2017, 543, 15. [CrossRef] [PubMed] 
16. Tacconelli, E.; Carrara, E.; Savoldi, A.; Harbarth, S.; Mendelson, M.; Monnet, D.L.; Pulcini, C.; Kahlmeter, G.; Kluytmans, J.; Carmeli, Y.; et al. Discovery, research, and development of new antibiotics: The WHO priority list of antibiotic-resistant bacteria and tuberculosis. Lancet Infect. Dis. 2018, 18, 318-327. [CrossRef]

17. Clatworthy, A.E.; Pierson, E.; Hung, D.T. Targeting virulence: A new paradigm for antimicrobial therapy. Nat. Chem. Biol. 2007, 3, 541-548. [CrossRef] [PubMed]

18. Curran, C.S.; Bolig, T.; Torabi-Parizi, P. Mechanisms and Targeted therapies for Pseudomonas aeruginosa lung infection. Am. J. Respir. Crit. Care Med. 2018, 197, 708-727. [CrossRef] [PubMed]

19. Wang, Y.; Cao, Q.; Cao, Q.; Gan, J.; Sun, N.; Yang, C.-G.; Bae, T.; Wu, M.; Lan, L. Histamine activates HinK to promote the virulence of Pseudomonas aeruginosa. Sci. Bull. 2021, in press. [CrossRef]

20. Tamber, S.; Hancock, R.E. On the mechanism of solute uptake in Pseudomonas. Front. Biosci. 2003, 8, s472-s483.

21. Lessie, T.G.; Phibbs, P.V., Jr. Alternative pathways of carbohydrate utilization in pseudomonads. Annu. Rev. Microbiol. 1984, 38, 359-388. [CrossRef]

22. Swanson, B.L.; Hager, P.; Phibbs, P.; Ochsner, U.; Vasil, M.L.; Hamood, A.N. Characterization of the 2-ketogluconate utilization operon in Pseudomonas aeruginosa PAO1. Mol. Microbiol. 2002, 37, 561-573. [CrossRef] [PubMed]

23. Udaondo, Z.; Ramos, J.L.; Segura, A.; Krell, T.; Daddaoua, A. Regulation of carbohydrate degradation pathways in Pseudomonas involves a versatile set of transcriptional regulators. Microb. Biotechnol. 2018, 11, 442-454. [CrossRef] [PubMed]

24. Mitchell, C.G.; Dawes, E.A. The role of oxygen in the regulation of glucose metabolism, transport and the tricarboxylic acid cycle in Pseudomonas aeruginosa. J. Gen. Microbiol. 1982, 128, 49-59. [CrossRef]

25. Daddaoua, A.; Corral-Lugo, A.; Ramos, J.-L.; Krell, T. Identification of GntR as regulator of the glucose metabolism in Pseudomonas aeruginosa. Environ. Microbiol. 2017, 19, 3721-3733. [CrossRef] [PubMed]

26. Daddaoua, A.; Molina-Santiago, C.; De La Torre, J.; Krell, T.; Ramos, J.-L. GtrS and GltR form a two-component system: The central role of 2-ketogluconate in the expression of exotoxin A and glucose catabolic enzymes in Pseudomonas aeruginosa. Nucleic Acids Res. 2014, 42, 7654-7665. [CrossRef]

27. Sage, A.E.; Proctor, W.D.; Phibbs, P.V. A two-component response regulator, gltR, is required for glucose transport activity in Pseudomonas aeruginosa PAO1. J. Bacteriol. 1996, 178, 6064-6066. [CrossRef]

28. Chevalier, S.; Bouffartigues, E.; Bodilis, J.; Maillot, O.; Lesouhaitier, O.; Feuilloley, M.G.J.; Orange, N.; Dufour, A.; Cornelis, P. Structure, function and regulation of Pseudomonas aeruginosa porins. FEMS Microbiol. Rev. 2017, 41, 698-722. [CrossRef]

29. Del Castillo, T.; Duque, E.; Ramos, J.L. A set of activators and repressors control peripheral glucose pathways in Pseudomonas putida to yield a common central intermediate. J. Bacteriol. 2008, 190, 2331-2339. [CrossRef]

30. Brint, J.M.; Ohman, D.E. Synthesis of multiple exoproducts in Pseudomonas aeruginosa is under the control of RhlR-RhII, another set of regulators in strain PAO1 with homology to the autoinducer-responsive LuxR-LuxI family. J. Bacteriol. 1995, 177, 7155-7163. [CrossRef]

31. Abril, M.A.; Michan, C.; Timmis, K.N.; Ramos, J.L. Regulator and enzyme specificities of the TOL plasmid-encoded upper pathway for degradation of aromatic hydrocarbons and expansion of the substrate range of the pathway. J. Bacteriol. 1989, 171, 6782-6790. [CrossRef]

32. Hoang, T.T.; Karkhoff-Schweizer, R.R.; Kutchma, A.J.; Schweizer, H.P. A broad-host-range Flp-FRT recombination system for site-specific excision of chromosomally-located DNA sequences: Application for isolation of unmarked Pseudomonas aeruginosa mutants. Gene 1998, 212, 77-86. [CrossRef]

33. Jansons, I.; Touchie, G.; Sharp, R.; Almquist, K.; Farinha, M.A.; Lam, J.S.; Kropinski, A.M. Deletion and transposon mutagenesis and sequence analysis of the pRO1600 OriR region found in the broad-host-range plasmids of the pQF series. Plasmid 1994, 31, 265-274. [CrossRef] [PubMed]

34. Becher, A.; Schweizer, H.P. Integration-proficient Pseudomonas aeruginosa vectors for isolation of single-copy chromosomal lacZ and lux gene fusions. Biotechniques 2000, 29, 948-950. [CrossRef]

35. Kulasekara, H.D.; Ventre, I.; Kulasekara, B.R.; Lazdunski, A.; Filloux, A.; Lory, S. A novel two-component system controls the expression of Pseudomonas aeruginosa fimbrial cup genes. Mol. Microbiol. 2004, 55, 368-380. [CrossRef] [PubMed]

36. Yang, N.; Ding, S.; Chen, F.; Zhang, X.; Xia, Y.; Di, H.; Cao, Q.; Deng, X.; Wu, M.; Wong, C.C.L.; et al. The Crc protein participates in down-regulation of the Lon gene to promote rhamnolipid production and rhl quorum sensing in Pseudomonas aeruginosa. Mol. Microbiol. 2015, 96, 526-547. [CrossRef]

37. Chen, F.; Di, H.; Wang, Y.; Cao, Q.; Xu, B.; Zhang, X.; Yang, N.; Liu, G.; Yang, C.-G.; Xu, Y.; et al. Small-molecule targeting of a diapophytoene desaturase inhibits S. aureus virulence. Nat. Chem. Biol. 2016, 12, 174-179. [CrossRef]

38. Cao, Q.; Wang, Y.; Chen, F.; Xia, Y.; Lou, J.; Zhang, X.; Yang, N.; Sun, X.; Zhang, Q.; Zhuo, C.; et al. A novel signal transduction pathway that modulates rhl quorum sensing and bacterial virulence in Pseudomonas aeruginosa. PLoS Pathog. 2014, 10, e1004340. [CrossRef]

39. Lo, M.-C.; Aulabaugh, A.; Jin, G.; Cowling, R.; Bard, J.; Malamas, M.; Ellestad, G. Evaluation of fluorescence-based thermal shift assays for hit identification in drug discovery. Anal. Biochem. 2004, 332, 153-159. [CrossRef]

40. Damian, L. Isothermal titration calorimetry for studying protein-ligand interactions. In Advanced Structural Safety Studies; Springer Science and Business Media LLC: New York, NY, USA, 2013; Volume 1008, pp. 103-118. 
41. Jones, C.J.; Newsom, D.; Kelly, B.; Irie, Y.; Jennings, L.K.; Xu, B.; Limoli, D.H.; Harrison, J.J.; Parsek, M.R.; White, P.; et al. ChIP-Seq and RNA-Seq reveal an AmrZ-mediated mechanism for cyclic di-GMP synthesis and biofilm development by Pseudomonas aeruginosa. PLoS Pathog. 2014, 10, e1003984. [CrossRef]

42. Sala, C.; Haouz, A.; Saul, F.A.; Miras, I.; Rosenkrands, I.; Alzari, P.M.; Cole, S.T. Genome-wide regulon and crystal structure of BlaI (Rv1846c) from Mycobacterium tuberculosis. Mol. Microbiol. 2009, 71, 1102-1116. [CrossRef]

43. Zhang, Y.; Liu, T.; Meyer, C.A.; Eeckhoute, J.; Johnson, D.J.; Bernstein, B.E.; Nusbaum, C.; Myers, R.M.; Brown, M.; Li, W.; et al. Model-based analysis of ChIP-Seq (MACS). Genome Biol. 2008, 9, R137. [CrossRef]

44. Bailey, T.L.; Boden, M.; Buske, F.A.; Frith, M.; Grant, C.E.; Clementi, L.; Ren, J.; Li, W.W.; Noble, W.S. MEME SUITE: Tools for motif discovery and searching. Nucleic Acids Res. 2009, 37, w202-w208. [CrossRef]

45. Zianni, M.; Tessanne, K.; Merighi, M.; Laguna, R.; Tabita, F. Identification of the DNA bases of a DNase I footprint by the use of dye primer sequencing on an automated capillary DNA analysis instrument. J. Biomol. Tech. 2006, 17, $103-113$.

46. Sun, Z.; Che, Y.; Yang, C.; Yang, S.; Gu, Y.; Jiang, W. A novel three-component system-based regulatory model for D-xylose sensing and transport in Clostridium beijerinckii. Mol. Microbiol. 2015, 95, 576-589. [CrossRef] [PubMed]

47. Karimova, G.; Pidoux, J.; Ullmann, A.; Ladant, D. A bacterial two-hybrid system based on a reconstituted signal transduction pathway. Proc. Natl. Acad. Sci. USA 1998, 95, 5752-5756. [CrossRef]

48. Cox, J.; Mann, M. MaxQuant enables high peptide identification rates, individualized p.p.b.-range mass accuracies and proteomewide protein quantification. Nat. Biotechnol. 2008, 26, 1367-1372. [CrossRef]

49. Cao, Q.; Yang, N.; Wang, Y.; Xu, C.; Zhang, X.; Fan, K.; Chen, F.; Liang, H.; Zhang, Y.; Deng, X.; et al. Mutation-induced remodeling of the BfmRS two-component system in Pseudomonas aeruginosa clinical isolates. Sci. Signal. 2020, 13, eaaz1529. [CrossRef]

50. Lee, Y.-J.; Jang, H.-J.; Chung, I.-Y.; Cho, Y.-H. Drosophila melanogaster as a polymicrobial infection model for Pseudomonas aeruginosa and Staphylococcus aureus. J. Microbiol. 2018, 56, 534-541. [CrossRef]

51. Kohlstedt, M.; Wittmann, C. GC-MS-based ${ }^{13} \mathrm{C}$ metabolic flux analysis resolves the parallel and cyclic glucose metabolism of Pseudomonas putida KT2440 and Pseudomonas aeruginosa PAO1. Metab. Eng. 2019, 54, 35-53. [CrossRef]

52. Daddaoua, A.; Fillet, S.; Fernández, M.; Udaondo, Z.; Krell, T.; Ramos, J.L. Genes for carbon metabolism and the ToxA virulence factor in Pseudomonas aeruginosa are regulated through molecular interactions of PtxR and PtxS. PLoS ONE 2012, 7, e39390. [CrossRef] [PubMed]

53. Stinson, M.W.; Cohen, M.A.; Merrick, J.M. Purification and properties of the periplasmic glucose-binding protein of Pseudomonas aeruginosa. J. Bacteriol. 1977, 131, 672-681. [CrossRef] [PubMed]

54. Modak, A.; Bhaumik, P.; Phale, P.S. Periplasmic glucose-binding protein from Pseudomonas putida CSV86-Identification of the glucose-binding pocket by homology-model-guided site-specific mutagenesis. FEBS J. 2013, 281, 365-375. [CrossRef] [PubMed]

55. Pandey, S.; Modak, A.; Phale, P.S.; Bhaumik, P. High resolution structures of periplasmic glucose-binding protein of Pseudomonas putida CSV86 reveal structural basis of its substrate specificity. J. Biol. Chem. 2016, 291, 7844-7857. [CrossRef]

56. Wolfe, A.J. The acetate switch. Microbiol. Mol. Biol. Rev. 2005, 69, 12-50. [CrossRef] [PubMed]

57. Klockgether, J.; Munder, A.; Neugebauer, J.; Davenport, C.F.; Stanke, F.; Larbig, K.D.; Heeb, S.; Schöck, U.; Pohl, T.M.; Wiehlmann, L.; et al. Genome diversity of Pseudomonas aeruginosa PAO1 laboratory strains. J. Bacteriol. 2009, 192, 1113-1121. [CrossRef] [PubMed]

58. Sidorenko, J.; Jatsenko, T.; Kivisaar, M. Ongoing evolution of Pseudomonas aeruginosa PAO1 sublines complicates studies of DNA damage repair and tolerance. Mutat. Res. Mol. Mech. Mutagen. 2017, 799, 26-37. [CrossRef]

59. Midgley, M.; Dawes, E.A. The regulation of transport of glucose and methyl alpha-glucoside in Pseudomonas aeruginosa. Biochem. J. 1973, 132, 141-154. [CrossRef]

60. Gill, S.K.; Hui, K.; Farne, H.; Garnett, J.P.; Baines, D.L.; Moore, L.S.; Holmes, A.H.; Filloux, A.; Tregoning, J.S. Increased airway glucose increases airway bacterial load in hyperglycaemia. Sci. Rep. 2016, 6, 27636. [CrossRef]

61. Stinson, M.W.; Cohen, M.A.; Merrick, J.M. Isolation of dicarboxylic acid- and glucose-binding proteins from Pseudomonas aeruginosa. J. Bacteriol. 1976, 128, 573-579. [CrossRef]

62. Temple, L.; Cuskey, S.M.; Perkins, R.E.; Bass, R.C.; Morales, N.M.; Christie, G.E.; Olsen, R.H.; Phibbs, P.V. Analysis of cloned structural and regulatory genes for carbohydrate utilization in Pseudomonas aeruginosa PAO. J. Bacteriol. 1990, 172, 6396-6402. [CrossRef]

63. O'Callaghan, J.; Reen, F.J.; Adams, C.; Casey, P.G.; Gahan, C.G.M.; O'Gara, F. A novel host-responsive sensor mediates virulence and type III secretion during Pseudomonas aeruginosa-host cell interactions. Microbiology 2012, 158, 1057-1070. [CrossRef]

64. Darias, J.-A.R.; Yang, Y.; Sourjik, V.; Krell, T. Correlation between signal input and output in PctA and PctB amino acid chemoreceptor of Pseudomonas aeruginosa. Mol. Microbiol. 2015, 96, 513-525. [CrossRef] [PubMed]

65. Martín-Mora, D.; Ortega, Á.; Matilla, M.A.; Martínez-Rodríguez, S.; Gavira, J.A.; Krell, T. The molecular mechanism of nitrate chemotaxis via direct ligand binding to the PilJ domain of McpN. mBio 2019, 10, e02334-18. [CrossRef] [PubMed]

66. Ding, Y.; Liu, X.; Chen, F.; Di, H.; Xu, B.; Zhou, L.; Deng, X.; Wu, M.; Yang, C.-G.; Lan, L. Metabolic sensor governing bacterial virulence in Staphylococcus aureus. Proc. Natl. Acad. Sci. USA 2014, 111, E4981-E4990. [CrossRef]

67. Pantoliano, M.W.; Petrella, E.C.; Kwasnoski, J.D.; Lovanov, V.S.; Myslik, J.; Graf, E.; Carver, T.; Asel, E.; Springer, B.A.; Lane, P.; et al. High-density miniaturized thermal shift assays as a general strategy for drug discovery. J. Biomol. Screen. 2001, 6, 429-440. [CrossRef] 
68. Lequette, Y.; Rollet, E.; Delangle, A.; Greenberg, E.P.; Bohin, J.-P. Linear osmoregulated periplasmic glucans are encoded by the opgGH locus of Pseudomonas aeruginosa. Microbiology 2007, 153, 3255-3263. [CrossRef]

69. Wu, H.; Kato, J.; Kuroda, A.; Ikeda, T.; Takiguchi, N.; Ohtake, H. Identification and characterization of two chemotactic transducers for inorganic phosphate in Pseudomonas aeruginosa. J. Bacteriol. 2000, 182, 3400-3404. [CrossRef]

70. Davidson, A.L.; Dassa, E.; Orelle, C.; Chen, J. Structure, function, and evolution of bacterial ATP-binding cassette systems. Microbiol. Mol. Biol. Rev. 2008, 72, 317-364. [CrossRef]

71. Tetsch, L.; Jung, K. The regulatory interplay between membrane-integrated sensors and transport proteins in bacteria. Mol. Microbiol. 2009, 73, 982-991. [CrossRef]

72. Buelow, D.R.; Raivio, T.L. Three (and more) component regulatory systems-Auxiliary regulators of bacterial histidine kinases. Mol. Microbiol. 2010, 75, 547-566. [CrossRef]

73. Piepenbreier, H.; Fritz, G.; Gebhard, S. Transporters as information processors in bacterial signalling pathways. Mol. Microbiol. 2017, 104, 1-15. [CrossRef] [PubMed]

74. Gebhard, S. ABC transporters of antimicrobial peptides in Firmicutes bacteria-Phylogeny, function and regulation. Mol. Microbiol. 2012, 86, 1295-1317. [CrossRef] [PubMed]

75. Kuroda, A.; Kumano, T.; Taguchi, K.; Nikata, T.; Kato, J.; Ohtake, H. Molecular cloning and characterization of a chemotactic transducer gene in Pseudomonas aeruginosa. J. Bacteriol. 1995, 177, 7019-7025. [CrossRef] [PubMed]

76. Baker, E.H.; Wood, D.M.; Brennan, A.L.; Clark, N.; Baines, D.L.; Philips, B.J. Hyperglycaemia and pulmonary infection. Proc. Nutr Soc. 2006, 65, 227-235. [CrossRef] [PubMed]

77. Pezzulo, A.A.; Gutiérrez, J.; Duschner, K.S.; McConnell, K.S.; Taft, P.J.; Ernst, S.E.; Yahr, T.L.; Rahmouni, K.; Klesney-Tait, J.; Stoltz, D.A.; et al. Glucose depletion in the airway surface liquid is essential for sterility of the airways. PLoS ONE 2011, 6, e16166. [CrossRef] [PubMed]

78. Garnett, J.P.; Gray, M.A.; Tarran, R.; Brodlie, M.; Ward, C.; Baker, E.H.; Baines, D.L. Elevated paracellular glucose flux across cystic fibrosis airway epithelial monolayers is an important factor for pseudomonas aeruginosa growth. PLoS ONE 2013, 8, e76283. [CrossRef]

79. Leclercq, A.; Gauthier, B.; Rosner, V.; Weiss, L.; Moreau, F.; Constantinescu, A.; Kessler, R. Early assessment of glucose abnormalities during continuous glucose monitoring associated with lung function impairment in cystic fibrosis patients. J. Cyst. Fibros. 2014, 13, 478-484. [CrossRef]

80. Oliveira, T.L.; Candeia-Medeiros, N.; Cavalcante-Araújo, P.M.; Melo, I.S.; Fávaro-Pípi, E.; Fátima, L.A.; Rocha, A.A.; Goulart, L.R.; Machado, U.F.; Campos, R.R.; et al. SGLT1 activity in lung alveolar cells of diabetic rats modulates airway surface liquid glucose concentration and bacterial proliferation. Sci. Rep. 2016, 6, 21752. [CrossRef]

81. Åstrand, A.; Wingren, C.; Benjamin, A.; Tregoning, J.S.; Garnett, J.P.; Groves, H.; Gill, S.; Orogo-Wenn, M.; Lundqvist, A.J.; Walters, D.; et al. Dapagliflozin-lowered blood glucose reduces respiratory Pseudomonas aeruginosa infection in diabetic mice. Br. J. Pharmacol. 2017, 174, 836-847.

82. Baker, E.H.; Baines, D.L. Airway glucose homeostasis: A new target in the prevention and treatment of pulmonary infection. Chest 2018, 153, 507-514. [CrossRef]

83. Yang, L.; Jelsbak, L.; Marvig, R.L.; Damkiaer, S.; Workman, C.T.; Rau, M.H.; Hansen, S.K.; Folkesson, A.; Johansen, H.K.; Ciofu, O.; et al. Evolutionary dynamics of bacteria in a human host environment. Proc. Natl. Acad. Sci. USA 2011, 108, 7481-7486. [CrossRef] [PubMed]

84. Marvig, R.L.; Johansen, H.K.; Molin, S.; Jelsbak, L. Genome analysis of a transmissible lineage of Pseudomonas aeruginosa Reveals pathoadaptive mutations and distinct evolutionary paths of hypermutators. PLoS Genet. 2013, 9, e1003741. [CrossRef] [PubMed] 